\title{
A technical survey on tire-road friction estimation
}

\author{
Seyedmeysam KHALEGHIAN ${ }^{1, *}$, Anahita EMAMI ${ }^{2}$, Saied TAHERI ${ }^{1}$ \\ ${ }^{1}$ Center for Tire Research (CenTiRe), Department of Mechanical Engineering, Virginia Tech, Blacksburg, VA 24061, United States \\ ${ }^{2}$ Department of Biomedical Engineering and Mechanics, Virginia Tech, Blacksburg, VA 24061, United States \\ Received: 23 September 2016 / Revised: 04 November 2016 / Accepted: 24 January 2017 \\ (C) The author(s) 2017. This article is published with open access at Springerlink.com
}

\begin{abstract}
Lack of driver's knowledge about the abrupt changes in pavement's friction and poor performance of the vehicle's stability, traction, and ABS controllers on the low friction surfaces are the most important factors affecting car crashes. Due to its direct relation to vehicle stability, accurate estimation of tire-road friction is of interest to all vehicle and tire companies. Many studies have been conducted in this field and researchers have used different tools and have proposed different algorithms. This literature survey introduces different approaches, which have been widely used to estimate the friction or other related parameters, and covers the recent literature that contains these methodologies. The emphasize of this review paper is on the algorithms and studies, which are more popular and have been repeated several times. The focus has been divided into two main groups: experiment-based and model-based approaches. Each of these main groups has several sub-categories, which are explained in the next few sections. Several summary tables are provided in which the overall feature of each approach is reviewed that gives the reader the general picture of different algorithms, which are widely used in friction estimation studies.
\end{abstract}

Keywords: tire-road friction; friction estimation; model-based approach; experiment-based approach

\section{Introduction}

Approximately 120,000 people were killed on US roadways between 2010-2013 [1-3]. Even in the case of non-fatal crashes, the economic costs are undeniably high $[4,5]$. Due to the large number of fatalities and the high economic costs, different studies have been conducted on the effects of different factors on car crashes $[6,7]$.

Twenty-four percent of all crashes are weather related, which occur on icy, snowy, or wet pavement or in the presence of rain, sleet, fog and snow [8]. Several studies have been conducted on crashes during rainfall and snowfall [9-12]. It was observed in a study on crashes before and after rain in Calgary and Edmonton that the crash rate is $70 \%$ higher on the wet pavement [13]. In a similar study, it was shown that the crash frequency on wet roads is twice the rate of the crashes on dry pavements [14]. This high rate of weather related crashes is mainly attributed to the drivers overestimating the pavement friction, and the effect of bad weather condition on the vehicle stability and safety controllers.

Tire-road friction estimation is one of the most important problems for both vehicle and tire industries that can decrease the number of weather related crashes dramatically. The effect of tire-road friction force on vehicle performance and stability and on the performance of traction and ABS controllers is undeniable [15-19].

Different studies have developed and used different algorithms to estimate the tire-road friction. Based on the approaches that they have followed, all of the related research can be divided into the following two categories:

1-Experiment-based;

2-Model-based.

In experiment-based approaches, it is attempted to

* Corresponding author: Seyedmeysam KHALEGHIAN, E-mail: meysam@vt.edu 
find a correlation between the sensor data (acoustic sensors, temperature sensor, etc.) and tire-road frictionrelated parameters. The model-based approaches try to estimate the friction using simplified mathematical models, which can be divided into three sub-categories: wheel and vehicle dynamic based approaches, slip based approaches, and tire model based approaches.

In vehicle dynamic base approached, different dynamic models (single wheel model, bicycle model, planar model, etc.) are used along with an estimation algorithm (recursive least square, steady state and extended Kalman filter, sliding mode observer, etc.) to estimate the tire-road friction force and other friction-related parameters such as slip ratio, slip angle, etc. Tire model based approaches use the friction force and slip data along with one of the tire models (Magic formula, Brush model, LuGre model, etc.) to estimate the maximum tire road friction coefficient. In slip base approaches it is assumed that the value of friction in the saturated area of $\mu$-slip curve can be estimated based on the slope of the curve in low slip region (linear region).

This study presents a technical survey of tire-road friction estimation research. For each of the above approaches, first, the method is explained briefly and then the review of the literature on the subject is presented. The rest of the paper is organized as follows: first, the tire-road friction force and aligning moment are introduced; the experiment-based friction estimation approaches are discussed in the second section. The model based friction estimation algorithms are reviewed in the third section followed by the conclusions in the last section.

Tire-road friction coefficient and self-aligning moment

In order to start with different friction estimation approaches, it is required to define the tire forces, aligning moment, and friction coefficient. Free body diagram of a single wheel is shown in Fig. 1, which $F_{x}, F_{y}, F_{z}$ are longitudinal, lateral, and normal tire forces, respectively. The normalized tire traction force is defined as [20]:

$$
\rho=\frac{\sqrt{F_{x}^{2}+F_{y}^{2}}}{F_{z}}
$$

where its maximum value is called the friction

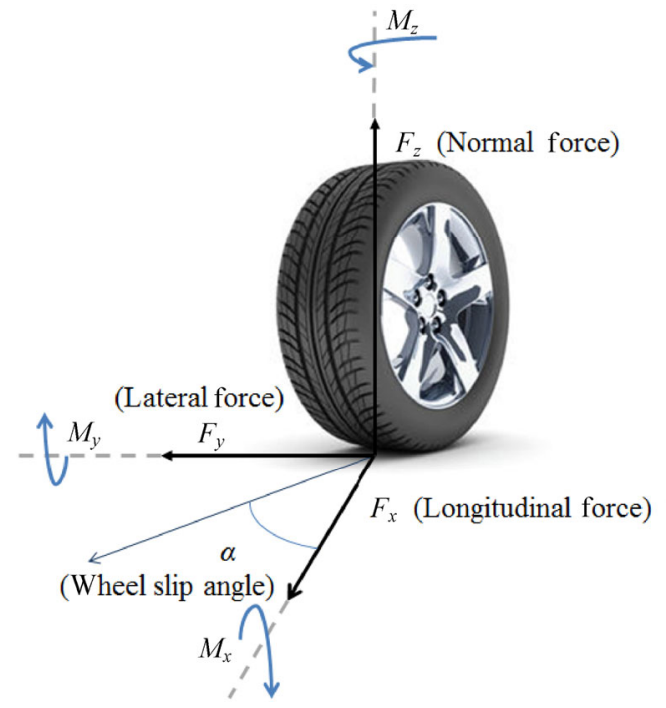

Fig. 1 Free body diagram of a single wheel.

coefficient $(\mu)$. The wheel aligning moment is defined as the tendency to align the wheel plane with the direction of wheel travel, which is caused by steering geometry and side deformation of a tire, which moves forward and has nonzero slip angle.

\section{Experiment-based}

Figure 2 demonstrates the main philosophy behind experiment-based approaches. As it is shown in Fig. 2, most of the experiment-based methods use sensor measurements of the friction-related parameters (tire noise, tire longitudinal or lateral deformation, etc.) and try to correlate these parameters to tire-road friction [21, 22].

Based on the sensor type and the parameter which is used for this estimation, experiment-based approaches can be categorized as follows.

\subsection{Optical sensors and cameras}

Optical sensors and cameras are used to detect surface properties related to friction. Using optical sensors

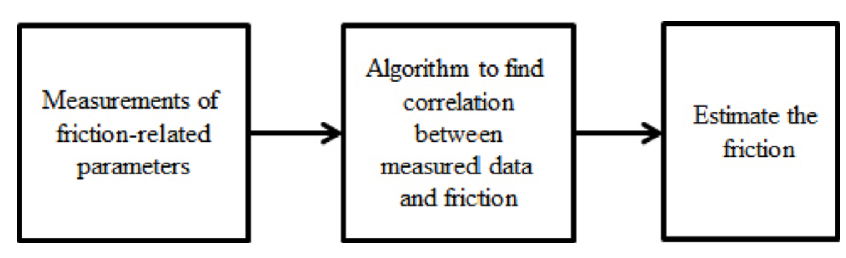

Fig. 2 Experiment-based flowchart diagram. 
to measure infrared light at different wavelengths reflected from the roads, the surface type (dry, wet, icy, snowy, etc.) can be identified. The principal of road-eye sensors is shown in Fig. 3 [23]. The other use of optical sensors is to estimate the sidewall deformation and correlate it with friction [24-26].

Cameras are also used to identify the texture of different surfaces. Once the texture is evaluated, a neural network can be trained to estimate the surface friction [27]. The conventional methods of detecting road conditions are [28]:

- Detection by color difference: It uses the ratios of color signals ( $R, G$ and $B$ ) to detect road condition.

- Detection by pattern matching: This technique uses geometrical features along with pixel density to estimate the condition of the road.

- Detection by infrared rays: Infrared can be used to detect the presence of water as water has a relatively large absorption band in the infrared range.

- Detection by difference in polarized level: It uses a difference between horizontal and vertical polarization to detect road condition.

What follows is the review of the papers that have used optical sensors for friction estimation. Holzmann

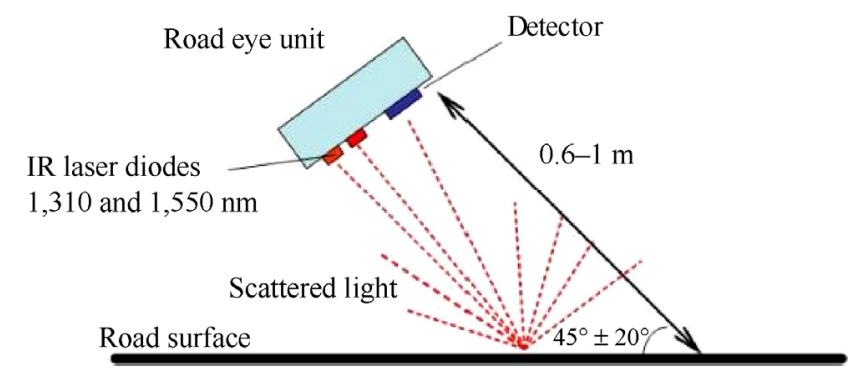

Fig. 3 The schematic of using optimal sensor to identify different surfaces [23]. et al. [29] used cameras and microphones for estimating the friction coefficient. The image captured by the camera was analyzed for the luminance and neighborhood of pixels. Microphone was used as a reactive measurement to improve the accuracy of the estimation; the frequency range of $100-600 \mathrm{~Hz}$ was analyzed. Kuno and Sugiura [28] used a CCD camera to detect the road condition. They detected the distribution of gloss on road surface due to presence of water using the high and low levels of luminance signals. Jokela et al. [30] used two methods of measurement: polarization change and graininess analysis. The amount of vertical and horizontal polarized light reflecting from the surface was used to detect the road surface condition. Graininess analysis is done by using a low pass filter on the image making it blurry and comparing the contrast with the original image.

\subsection{Acoustic sensor}

Acoustic sensors are used to classify the road surface type/condition (asphalt, concrete, wet, dry, etc.) based on the tire noise. In some of the studies, the acoustic sensors were attached to the vehicle's chassis [31]. Figure 4 demonstrates the algorithm, which uses support vector machine (SVM) to classify different surfaces based on tire noise.

Some other studies have used a microphone, installed at a fixed road location, to record the noise generated by the vehicles passing by and use the recorded data to estimate the pavement status [32-35].

\subsection{Tire tread sensors}

Tire tread sensors are used to monitor the interaction between tire and the road, and to estimate the

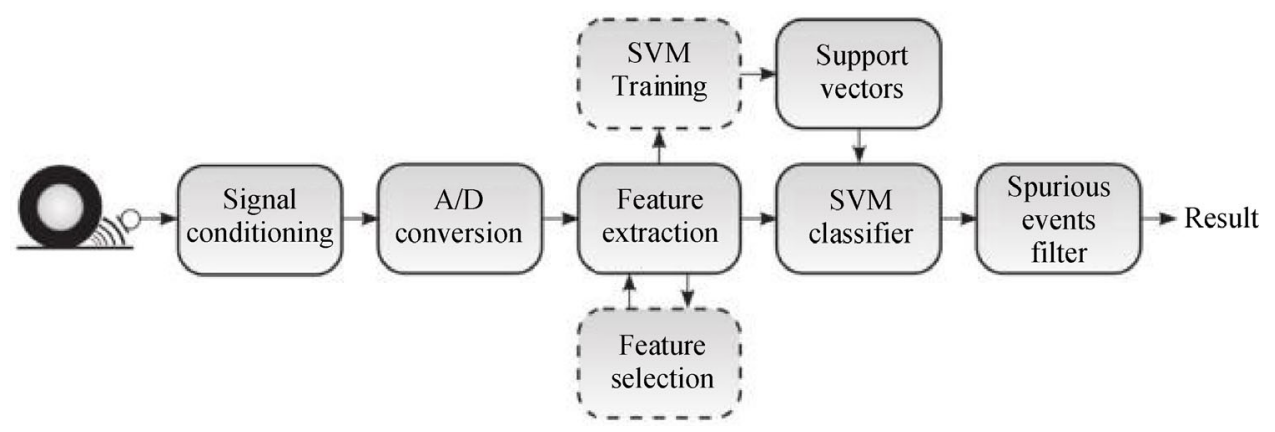

Fig. 4 Friction estimation algorithm using acoustic sensors. Reproduce with permission from Ref. [31]. Copyright Elsevier, 2014. 
deflection of tread elements inside the contact patch. The sensor types are mostly accelerometer and piezo electric and magnetic sensors. Erdogan et al. used the piezoelectric sensor inside the tire (in the tread area), which estimates lateral deflection profile of the carcass and uses it to estimate the friction [36]. Magnets vulcanized into the tread of a Kevlar-belted tire are also used in some studies to measure the deflection of the tread in $x, y$, and $z$ directions as a function of its position inside the contact patch [21, 22, 37-39]. Using the fact that the tread deformation is caused by the total force acting on the tire, the friction is estimated. In other studies, tri-axial accelerometers attached to the innerliner of the tire, shown in Fig. 5(b), are used to estimate the friction [40].

Matilainen and Tuononen [41, 42] used the signals from the tri-axial accelerometer inside the tire to estimate contact patch length. The algorithm detects two acceleration peaks in the longitudinal acceleration signal and uses it along with wheel angular speed to estimate contact patch. Khaleghian et al. [43, 44] and Singh et al. [40] utilized a tri-axial accelerometer attached to the innerliner of the tire; using a neural network algorithm, they estimated the tire normal load. Niskanen and Tuononen [45-47] used three tri-axial accelerometers inside the tire to find friction indicators on smooth ice and concrete surfaces. The radial acceleration signal from the accelerometer is analyzed at the leading edge of the contact patch for friction

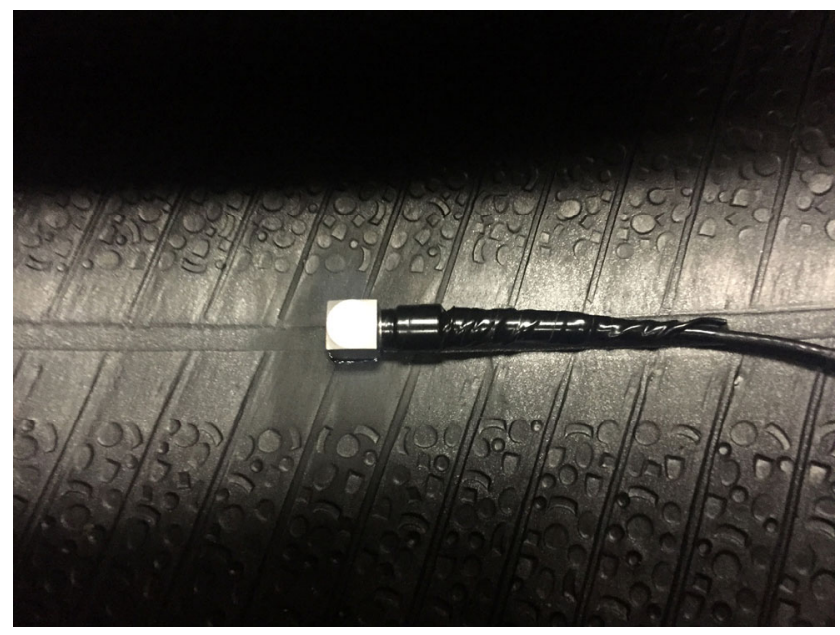

Fig. 5 Using tread sensors (tri-axial accelerometer) to estimate the friction. Reproduce with permission from Ref. [40]. Copyright Khaleghian, 2017. indicators. They have stated that the vibration in the leading edge due to slip on low friction surfaces can be used to determine the road surface type.

In addition to the studies and approaches that were introduced in this section, several patents have been submitted, and have used different experiment based methods to estimate the friction or other related parameters; some of these patents are summarized in Table 1.

Although the tire-road friction can be estimated using some of the experiment based approaches, in most cases their accuracy is reduced when the testing condition deviates from the condition under which the algorithm was trained. In order to make the estimation algorithms more robust and take the dynamic of the vehicle into account, model-based approaches are introduced.

\section{Model-based}

Model-based approaches contain all the studies that use a mathematical/dynamical model to estimate the friction. No need of any expensive special sensor which is standard on today's vehicles and accuracy and repeatability of the results in most of the cases, makes this category more popular as compared with experiment-based approaches. The model-based studies can be divided into three main groups: wheel and vehicle dynamic based, tire model based, and slip-slope based approaches.

\subsection{Wheel and vehicle dynamics based}

Studies, which are based on this approach, use the dynamical model of the system, in which some of the states can be measured (like angular velocity of the wheel) and some other states cannot be measured (like friction force, longitudinal speed, etc.). Based on dynamical model of the system and the measured states, the rest of the states can be estimated using different estimation algorithms such as recursive least square (RLS), Kalman filter, etc. The general flowchart of algorithm which is used in most of vehicle dynamic based studies is shown in Fig. 6.

Some of the most common dynamical models in the friction estimation studies are wheel tire model, roll 
Table 1 Summary of the patents which have used experiment based methods.

\begin{tabular}{|c|c|c|}
\hline Inventor name & Estimated parameters & Summary of invention \\
\hline Klein [48] & Friction coefficient & $\begin{array}{l}\text { He used a steering system which was controlled by a control module. They estimated the } \\
\text { steering gain and steering load hysteresis along with a reference, they determined the friction. }\end{array}$ \\
\hline Singh $[49,50]$ & $\begin{array}{l}\text { Tire normal load, } \\
\text { side slip-angle }\end{array}$ & $\begin{array}{l}\text { Two strain sensors are attached to the inner and outer sidewalls of a tire (sidewall strain } \\
\text { sensors), using the average power of these signals in different tire pressures to estimate the } \\
\text { normal load, also they developed an algorithm to estimate the side slip-angle based on } \\
\text { properties of strain signals (then vehicle dynamic based approach was used to estimate the } \\
\text { tire longitudinal and lateral force). }\end{array}$ \\
\hline Singh et al. [50] & $\begin{array}{l}\text { Tire normal load, } \\
\text { side slip-angle }\end{array}$ & $\begin{array}{l}\text { They used a set of strain sensors affixed to opposite sidewalls of the tire. Estimating the } \\
\text { slope difference in opposite sidewalls strain signals, they estimated the side slip angle. } \\
\text { They also estimated the tire normal load based on the average power of strain signal. }\end{array}$ \\
\hline Singh et al. [51] & Tire sidewall force & $\begin{array}{l}\text { They used a piezo film in one or both sidewalls of the tire. The sensor generates a signal } \\
\text { within the contact patch area (can be used to estimate the length of the contact patch), where } \\
\text { power of the signal indicates the sidewall deformation. The power to load map for different } \\
\text { tire pressure is used to estimate the sidewall force. }\end{array}$ \\
\hline Miyazaki [52] & $\begin{array}{l}\text { Tire forces, } \\
\text { friction coefficient }\end{array}$ & $\begin{array}{l}\text { Several strain sensors are attached to the vicinity of the wheel on the axle, which provide } \\
\text { the strain signals. The produced signals are used to estimate the tire forces and tire-road } \\
\text { friction coefficient (from the correlation between strain signals and desired parameters). }\end{array}$ \\
\hline Hattori [53] & $\begin{array}{l}\text { The strain state } \\
\text { of the tire }\end{array}$ & $\begin{array}{l}\text { A series of conductors composed of plurality of conductor pieces (embedded in lines at } \\
\text { specific interval in circumferential direction of the tire) are used to provide the strain states } \\
\text { of the tire. A monitoring device releases signal (pulse electromagnetic wave), also receive } \\
\text { the reflected signals from the foils. The time difference between radiation and reception in } \\
\text { different conditions is used to evaluate the strain stress of the tire. }\end{array}$ \\
\hline $\begin{array}{l}\text { Hillenmayer and } \\
\text { Kuchler [54] }\end{array}$ & $\begin{array}{l}\text { Tire static load, } \\
\text { nature of the } \\
\text { road surface }\end{array}$ & $\begin{array}{l}\text { A pressure sensor and a deformation sensor are used in the tire; using frequency-dependent } \\
\text { analysis on the sensor signal they estimate the static loading and the nature of the road } \\
\text { surfaces. }\end{array}$ \\
\hline $\begin{array}{l}\text { Miyoshi et al. } \\
\quad[55]\end{array}$ & $\begin{array}{l}\text { Tire longitudinal } \\
\text { force }\end{array}$ & $\begin{array}{l}\text { Two magnetic sensors are used to measure the rotation angle of the wheel and wheel axle. } \\
\text { Then they used a computing device to calculate the tire warp angle, which is derived by } \\
\text { the difference between tire rotational angle during load and no-load condition. Then they } \\
\text { estimated the tire longitudinal force as a function of tire warp angle. }\end{array}$ \\
\hline Sistonen [56] & $\begin{array}{l}\text { The friction on a } \\
\text { surface }\end{array}$ & $\begin{array}{l}\text { He developed a new device consist of a wheel, an arm which is attached to wheel axle and } \\
\text { a spring, which is attached between measuring wheel and its axle to estimate the friction. } \\
\text { The degree of rotation of the measuring wheel at the point, where the wheel starts to slid, is } \\
\text { used to estimate the friction. }\end{array}$ \\
\hline $\begin{array}{l}\text { Bell and Bell } \\
\quad[57]\end{array}$ & Friction coefficient & $\begin{array}{l}\text { They used tread force sensor, one end of the sensor is fixed on the tread and the other end is } \\
\text { on the tire structure, where slipping of small discrete tread element can be detected. Compiling } \\
\text { the sensor data of the tire deformation-induced tread gripping force, the friction coefficient } \\
\text { is estimated. }\end{array}$ \\
\hline $\begin{array}{l}\text { Abe and Sawa } \\
{[58]}\end{array}$ & $\begin{array}{l}\text { Dynamic friction } \\
\text { coefficient }\end{array}$ & $\begin{array}{l}\text { They developed a new device to measure the dynamic friction coefficient which includes a } \\
\text { disk with measuring rubber member, a driving disk adapted to rotate co-axially with the disk } \\
\text { and dynamometer interconnects the disk and the driving disk. A tachometer is also used to } \\
\text { measure the speed of the rubber. Using X-Y recorder, which records the output signals of } \\
\text { friction measuring portion and the tachometer, the friction coefficient is estimated. }\end{array}$ \\
\hline
\end{tabular}

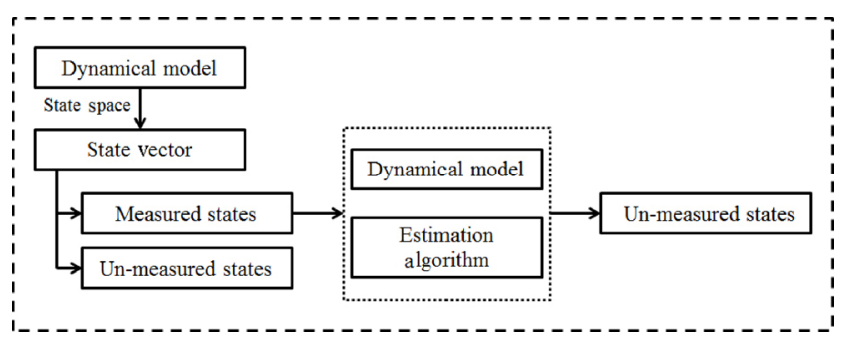

Fig. 6 The general flowchart for vehicle dynamic based approaches. dynamic model, bicycle model, quarter-car model, and four-wheel vehicle dynamic model, which are explained in more details next.

\subsubsection{Wheel dynamic model}

Free-body diagram of a single wheel is depicted in Fig. 7 in which, $F_{\text {rr }}$ is the rolling resistance force, and $T$ is the transmitted wheel torque. The equations of motion for this problem are as follow: 


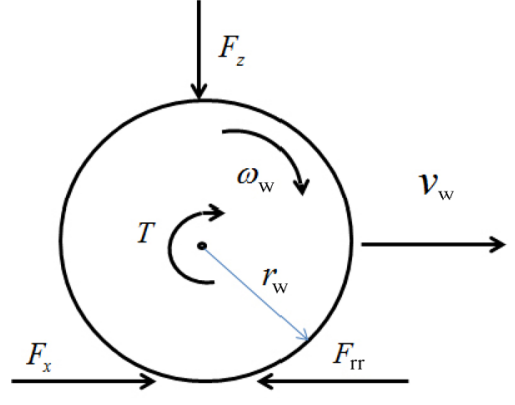

Fig. 7 Free body diagram of a single wheel.

$$
\begin{gathered}
m_{\mathrm{w}} \dot{v}_{x}=F_{x}-F_{\mathrm{rr}} \\
J_{\mathrm{w}} \dot{\omega}_{\mathrm{w}}=\left(T_{\mathrm{w}}-T_{\mathrm{b}}\right)-F_{x} r_{\mathrm{w}}-F_{\mathrm{rr}} r_{\mathrm{w}}
\end{gathered}
$$

where $m_{\mathrm{w}}$ is the total mass of the wheel, $J_{\mathrm{w}}$ is the moment of inertia of the wheel, and $T_{w}, T_{b}$ are the drive and brake torques, respectively. The value of wheel rolling resistance force can be calculated as:

$$
F_{\mathrm{rr}}=f_{\mathrm{r}} W
$$

where $W$ is the weight on the wheel and $f_{\mathrm{r}}$ is the rolling resistance coefficient that can be expressed as a function of tire pressure and wheel velocity. Several equations have been developed over years to estimate the rolling resistance. One suggests following equation for rolling on concrete surface [59]:

$$
f_{\mathrm{r}}=f_{\mathrm{o}}+3.24 f_{\mathrm{s}}\left(\frac{V}{100}\right)^{2.5}
$$

where $V$ is the speed in mph, $f_{\mathrm{r}}$ and $f_{\mathrm{o}}$ are basic coefficient and speed effect coefficient respectively that depend on inflation pressure. Equation (3) is widely used in the literature in order to estimate the tire longitudinal friction force $[18,60,61]$. However, the accuracy of estimated longitudinal force highly depends on the accuracy of the effective rolling radius of the tire $\left(r_{\mathrm{w}}\right)$. The effective rolling radius is presented as [20]:

$$
\begin{aligned}
r_{\mathrm{w}} & =\frac{\sin \left[\arccos \left(\frac{r_{\text {static }}}{r_{0}}\right)\right]}{\arccos \left(\frac{r_{\text {static }}}{r_{0}}\right)} \\
r_{\text {static }} & =r_{0}-\frac{F_{z}}{k_{\mathrm{t}}}
\end{aligned}
$$

where $r_{0}$ is the initial radius of the tire and $k_{\mathrm{t}}$ is the vertical stiffness of the tire. Wheel dynamic model is mostly used with a tire model in order to estimate the longitudinal force and longitudinal friction [62, 63]. Hsiao et al. [63] substituted the measured wheel torque and wheel angular velocity into Eq. (3), obtained from moment balance equation of each wheel, to estimate the tire longitudinal force. Rajamani et al. [64] used the measured data of angular wheel speed and proposed a sliding mode observer to estimate the tire longitudinal force based on single wheel dynamic model. Cho et al. [65] used the same approach to estimate the longitudinal tire force and showed that the estimated force is accurate for the low slip vehicle maneuvers. Rabhi et al. [66, 67] used a single wheel model with cascaded first and second sliding observers to estimate the contact force. They used the measured data of longitudinal speed of the vehicle, angular position of the wheel and wheel torque along with robust differentiator and sliding mode observer to estimate the velocity and acceleration of the wheel, longitudinal and vertical tire forces and friction coefficient.

\subsubsection{DOF roll dynamic model}

The most common vehicle models, which are used to estimate the roll dynamics of the vehicle, are 3DOF model, which represents lateral, yaw and roll motions of the vehicle, and 1DOF model, representing the roll dynamics.

The 1DOF roll dynamic model has practical advantages in comparison to 3DOF model, which does not need the cornering stiffness (which is not easy to be estimated), besides it is not sensitive to the nonlinear tire dynamics. For these reasons, 1DOF model is widely used in the vehicle state estimation studies. Figure 8 demonstrates the schematic of 1DOF vehicle roll model [68], where $k_{\text {roll }}, c_{\text {roll }}$ are roll stiffness and roll damping coefficients for the combination of tire-suspension, respectively (which are assumed to be constant), and $h_{\text {roll }}$ is the distance from the roll center to the vehicle CG. Assuming the roll axis is fixed and there is no vertical motion, the equation of motion is formulated as:

$$
\left(I_{x}+m_{\mathrm{s}} h_{\text {roll }}^{2}\right) \ddot{\phi}_{\text {chassis }}+c_{\text {roll }} \dot{\phi}_{\text {chassis }}+k_{\text {roll }} \phi_{\text {chassis }}=-m_{\mathrm{s}} h_{\text {roll }} a_{y, \mathrm{~m}}
$$

where $I_{x}+m_{\mathrm{s}} h^{2}$ roll is the moment of inertia around the roll axis, $I_{x}$ is the moment of inertia around $x$ axis and 


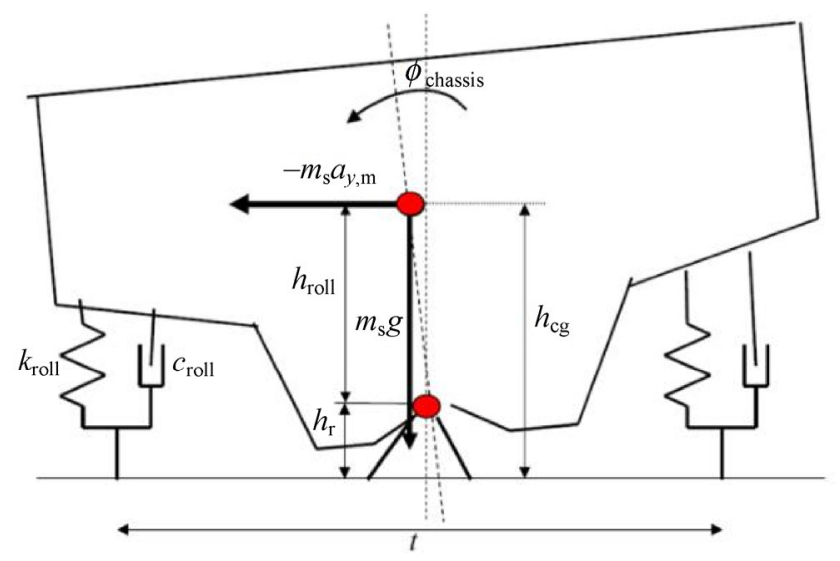

Fig. 8 The schematic of 1DOF roll vehicle model. Reproduce with permission from Ref. [68]. Copyright Singh, 2012.

$m_{\mathrm{s}}$ is the sprung mass of the vehicle. The vehicle roll dynamic model is mostly used to estimate the vehicle roll angle, which is a key factor to obtain the normal load at the wheels. Some of the studies, which have used roll dynamic model, are summarized in Table 2.

\subsubsection{Quarter car model}

The quarter car model is a 2DOF model which is mostly used to model the vertical dynamic (especially suspension) of the car. As it is shown in Fig. 9, quarter car model is represented with two lumped masses, $m_{\mathrm{qs}}, m_{\mathrm{qu}}$ (sprung mass and un-sprung mass), which are $\frac{1}{4}$ vehicle body mass and wheel mass respectively. The suspension system of the vehicle is presented as a set of spring damper system $\left(k_{s}, c_{s}\right)$ while the tire is presented as a single spring $\left(k_{\mathrm{u}}\right)$ (however in some other studies, tire is considered as set of spring-damper too).

The equations of the motion for the quarter-car vehicle model shown in Fig. 8 are presented as:

$$
\begin{aligned}
& m_{\mathrm{s}} \ddot{x}_{\mathrm{s}}+c_{\mathrm{s}}\left(\dot{x}_{\mathrm{s}}-\dot{x}_{\mathrm{u}}\right)+k_{\mathrm{s}}\left(x_{\mathrm{s}}-x_{\mathrm{u}}\right)=0 \\
& m_{\mathrm{u}} \ddot{x}_{\mathrm{u}}+c_{\mathrm{s}}\left(\dot{x}_{\mathrm{u}}-\dot{x}_{\mathrm{s}}\right)+\left(k_{\mathrm{u}}+k_{\mathrm{s}}\right) x_{\mathrm{u}}-k_{\mathrm{s}} x_{\mathrm{s}}=0
\end{aligned}
$$

Quarter car model is mainly used in friction estimation studies to obtain the tire normal force and road profile. Several studies have measured the vertical acceleration of the un-sprung mass and the suspension deflection and have used them to estimate the normal force using the following equation [75-77]:

$$
F_{z}=c_{\mathrm{s}}\left(\dot{x}_{\mathrm{s}}-\dot{x}_{\mathrm{u}}\right)+k_{\mathrm{s}}\left(x_{\mathrm{s}}-x_{\mathrm{u}}\right)-m_{\mathrm{u}} \ddot{x}_{\mathrm{u}}
$$

Doumiati et al. $[78,79]$ used the quarter car model to estimate tire normal load and the road profile. First, they used accelerometer measurements to calculate the vehicle body vertical position, and then used it as a measured state for Kalman filter to estimate the normal wheel load and road profile.

Next, the planar dynamic models of the vehicle are introduced; four-wheel vehicle model and its simplified version, bicycle model are discussed in more details which are widely used in vehicle state estimation studies.

\subsubsection{Four-wheel vehicle model}

Four-wheel vehicle model (also called two-track model) just considers the longitudinal, lateral and yaw motions of the vehicle, while roll, pitch, and vertical motion are ignored. The schematic of this model is shown in

\begin{tabular}{|c|c|c|c|}
\hline Authors & Measured states & Estimated states & Method \\
\hline Hac et al. [69] & $\begin{array}{l}\text { Lateral acceleration, } \\
\text { yaw rate }\end{array}$ & Roll angle & $\begin{array}{l}\text { Closed-loop adaptive observer was used to estimate the roll angle and } \\
\text { roll rate with respect to the road. }\end{array}$ \\
\hline Tsourapas et al. [70] & Load transfer ratio & $\begin{array}{l}\text { Vehicle roll } \\
\text { dynamic }\end{array}$ & $\begin{array}{l}\text { Two rolls over indexes are introduced and analyzed; these indexes are: } \\
\text { actual lateral transfer ratio (LTR) and predictive lateral transfer ratio } \\
\text { and predictive lateral transfer ratio (PLTR). }\end{array}$ \\
\hline Grip et al. [71] & Roll rate & Roll angle & $\begin{array}{l}\text { Combination of vehicle dynamics control system and a roll over } \\
\text { mitigation system is used to estimate the roll angle. }\end{array}$ \\
\hline $\begin{array}{l}\text { Chen et al. [72] } \\
\text { Ryu et al. [73] }\end{array}$ & $\begin{array}{l}\text { Lateral acceleration, } \\
\text { yaw rate }\end{array}$ & Roll angle & $\begin{array}{l}\text { They used a roll vehicle model (either 3DOF model or } 1 \mathrm{DOF} \text { model) } \\
\text { along with Kalman filter to estimate the roll angle. }\end{array}$ \\
\hline Cho et al. [74] & $\begin{array}{l}\text { Longitudinal speed, } \\
\text { yaw and roll rate, } \\
\text { lateral acceleration }\end{array}$ & Roll angle & $\begin{array}{l}\text { Vehicle state index based switching is used on the roll dynamic and } \\
\text { kinematic model to estimate the roll angle. }\end{array}$ \\
\hline
\end{tabular}
Fig. 10 [20], where $t$ is the track length, $l_{\mathrm{f}}, l_{\mathrm{r}}$ are the

Table 2 Some of the studies which have used roll dynamic model. 


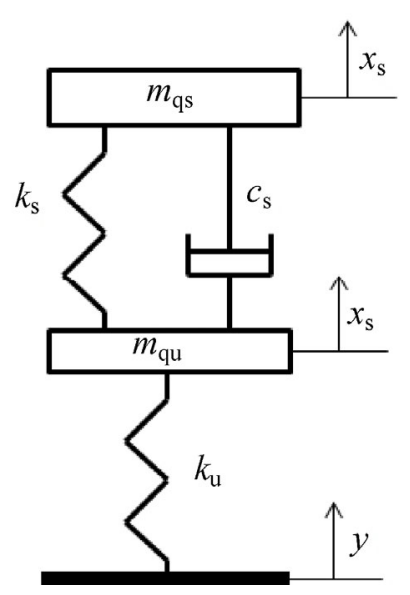

Fig. 9 Schematic of quarter car vehicle model.

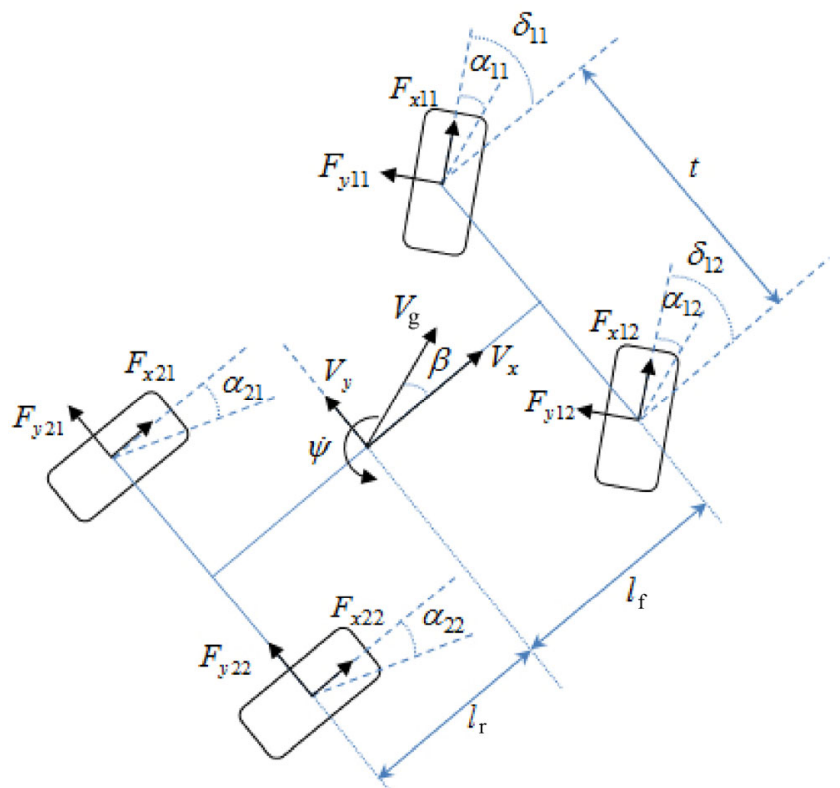

Fig. 10 The schematic of four wheel vehicle model.

distance of center of gravity of the vehicle (CG) from the front and rear axle respectively, $V_{\mathrm{g}}$ is the velocity of CG and $V_{x}, V_{y}$ are its component in $x$ and $y$ direction respectively. Also $\dot{\psi}$ is the yaw rate, $\delta$ is the steering angle and it is assumed that both front wheels have the same steering angle $\left(\delta_{11}=\delta_{12}\right)$. The equations of motion for this model are as follows [20]:

$$
\ddot{\psi}=\frac{1}{I_{z}}\left[\begin{array}{l}
l_{\mathrm{f}}\left[F_{y 11} \cos \delta+F_{y 12} \cos \delta+F_{x 11} \sin \delta+F_{x 12} \sin \delta\right] \\
-l_{\mathrm{r}}\left[F_{y 21}+F_{y 22}\right]+\frac{t}{2}\left[F_{y 11} \sin \delta-F_{y 12} \sin \delta\right. \\
\left.+F_{x 12} \cos \delta-F_{x 11} \cos \delta+F_{x 22}-F_{x 21}\right]
\end{array}\right]
$$

$$
\begin{aligned}
& \dot{\beta}=-\dot{\psi}+\frac{1}{m_{\mathrm{v}} V_{\mathrm{g}}}\left[\begin{array}{l}
-\left(F_{x 11}+F_{x 12}\right) \sin (\beta-\alpha) \\
+F_{y 11} \cos (\beta-\alpha)+F_{y 12} \cos (\beta-\alpha) \\
+F_{y 11} \cos (\beta-\alpha)+\left(F_{y 21}+F_{y 22}\right) \cos (\beta-\alpha) \\
-\left(F_{x 21}+F_{x 22}\right) \sin \beta
\end{array}\right] \\
& a_{y}=\frac{1}{m_{\mathrm{v}}}\left[\begin{array}{l}
F_{y 11} \cos \delta+F_{y 12} \cos \delta+F_{y 21}+F_{y 22} \\
+F_{x 11} \sin \delta+F_{x 12} \sin \delta
\end{array}\right] \\
& a_{x}=\frac{1}{m_{\mathrm{v}}}\left[\begin{array}{l}
-F_{y 11} \sin \delta-F_{y 12} \sin \delta+F_{x 21}+F_{x 22} \\
+F_{x 11} \cos \delta+F_{x 12} \cos \delta
\end{array}\right] \\
& \dot{V}_{x}=V_{y} \dot{\psi}+a_{x} \\
& \dot{V}_{y}=-V_{x} \dot{\psi}+a_{y} \\
& \dot{V}_{\mathrm{g}}=\frac{1}{m_{\mathrm{v}}}\left[\begin{array}{l}
\left(F_{x 11}+F_{x 12}\right) \cos (\beta-\delta)+F_{y 11} \sin (\beta-\delta) \\
+F_{y 12} \sin (\beta-\delta)+\left(F_{x 21}+F_{x 22}\right) \cos \beta \\
+\left(F_{x 21}+F_{x 22}\right) \cos \beta \\
+\left(F_{y 21}+F_{y 22}\right) \sin \beta
\end{array}\right]
\end{aligned}
$$

where $I_{z}$ is the moment of inertia of the car around $\mathrm{z}$ axis, $m_{\mathrm{v}}$ is the vehicle mass and $\beta$ is the vehicle side slip angle. Table 3 summarizes some of the studies which have used the four-wheel vehicle dynamic model to estimate the friction force, friction coefficient or other parameter related to friction estimation problem. The simplified version of four-wheel vehicle model is bicycle model (also called single-track model) which is introduced in the next section.

\subsubsection{Bicycle model}

The schematic of the bicycle model is shown in Fig. 11, which was introduced by Segel in 1956 [20]. The bicycle mode is widely used to describe the handling dynamics of the vehicle, in which vertical and roll motions are not taken into account.

The simplified equations of motion for the bicycle model are as follow:

$$
\begin{gathered}
\ddot{\psi}=\frac{1}{I_{z}}\left[l_{f}\left[F_{x 1} \sin \delta+F_{y 1} \cos \delta\right]-l_{\mathrm{r}} F_{y 2}\right] \\
\dot{\beta}=\frac{1}{m_{\mathrm{v}} V_{\mathrm{g}}}\left[\begin{array}{l}
-F_{x 1} \sin (\beta-\delta)+F_{y 1} \sin (\beta-\delta) \\
+F_{y 2} \cos \beta-F_{x 2} \sin \beta
\end{array}\right]-\dot{\psi} \\
\dot{V}_{\mathrm{g}}=\frac{1}{m_{\mathrm{v}}}\left[\begin{array}{l}
F_{x 1} \cos (\delta-\beta)-F_{y 1} \sin (\delta-\beta) \\
+F_{x 2} \cos \beta+F_{y 2} \sin \beta
\end{array}\right]
\end{gathered}
$$


Table 3 Some selective studies which have used four-wheel vehicle model.

\begin{tabular}{|c|c|c|c|}
\hline Authors & Measured states & Estimated states & Method \\
\hline $\begin{array}{l}\text { Samadi et al. } \\
{[80]}\end{array}$ & $\begin{array}{l}\text { Longitudinal acceleration, lateral } \\
\text { acceleration for the front and } \\
\text { rear axles, angular velocity of the } \\
\text { wheels }\end{array}$ & $\begin{array}{l}\text { Longitudinal tire force } \\
\text { for all wheels and lateral } \\
\text { force for front and rear } \\
\text { axles }\end{array}$ & $\begin{array}{l}\text { They used extended Kalman filter to estimate the tire } \\
\text { forces, they used Pacejka as the tire model and nonlinear } \\
\text { model for hydraulic braking system. }\end{array}$ \\
\hline $\begin{array}{l}\text { Baffet et al. } \\
\quad[81]\end{array}$ & $\begin{array}{l}\text { Yaw rate, velocity of CG, longi- } \\
\text { tudinal \& lateral acceleration }\end{array}$ & $\begin{array}{l}\text { Tire forces, vehicle } \\
\text { velocity, yaw rate }\end{array}$ & $\begin{array}{l}\text { They used extended Kalman filter (with random walk } \\
\text { model for the forces) to estimate the tire forces, then } \\
\text { they estimated the side-slip angle based on dynamic of } \\
\text { the problem. Cornering stiffness was estimated based on } \\
\text { the data of tire forces and side slip angle through another } \\
\text { Kalman filter algorithm. }\end{array}$ \\
\hline $\begin{array}{l}\text { Shim and } \\
\text { Margolis } \\
{[82,83]}\end{array}$ & $\begin{array}{l}\text { Longitudinal \& lateral accelera- } \\
\text { tion, steering angle, wheel angular } \\
\text { velocity }\end{array}$ & Tire forces & $\begin{array}{l}\text { They used four-wheel dynamic model and estimate the } \\
\text { tire forces base on the analytical tire model (relation } \\
\text { between the measured and estimated states) which they } \\
\text { proposed. }\end{array}$ \\
\hline $\begin{array}{l}\text { Doumiati et al. } \\
\text { [84-88] }\end{array}$ & $\begin{array}{l}\text { Longitudinal \& lateral accelera- } \\
\text { tion, steering angle, wheel angular } \\
\text { velocity, yaw and pitch rate, } \\
\text { suspension displacement }\end{array}$ & $\begin{array}{l}\text { Tire forces, vehicle side } \\
\text { slip angle }\end{array}$ & $\begin{array}{l}\text { They used vehicle roll model to estimate the tire normal } \\
\text { force and then used a four-wheel vehicle model dynamics } \\
\text { of the problem; using two observer (extended and } \\
\text { unscented Kalman filter) they estimated the tire force } \\
\text { and vehicle side slip angle. }\end{array}$ \\
\hline $\begin{array}{l}\text { Ghandour et } \\
\text { al. }[89,90]\end{array}$ & $\begin{array}{l}\text { Longitudinal \& lateral accelera- } \\
\text { tion, steering angle, wheel angular } \\
\text { velocity, yaw and pitch rate, } \\
\text { suspension displacement }\end{array}$ & $\begin{array}{l}\text { Tire lateral force and } \\
\text { side slip angle }\end{array}$ & $\begin{array}{l}\text { Using the roll vehicle model, they estimated the tire normal } \\
\text { load, then they used extended and unscented Kalman } \\
\text { filter to estimate the lateral force and side slip angle. }\end{array}$ \\
\hline $\begin{array}{l}\text { Ghandour et } \\
\text { al. [91] }\end{array}$ & $\begin{array}{l}\text { Longitudinal \& lateral accelera- } \\
\text { tion, steering angle, wheel angular } \\
\text { velocity, yaw and pitch rate, } \\
\text { suspension displacement }\end{array}$ & $\begin{array}{l}\text { Lateral load transfer, } \\
\text { lateral skid indicator }\end{array}$ & $\begin{array}{l}\text { They used the vehicle roll model for the normal load } \\
\text { then they proposed a maximum friction coefficient } \\
\text { estimation based algorithm to evaluate a lateral risk skid } \\
\text { indicator. }\end{array}$ \\
\hline $\begin{array}{l}\text { Dakhlallah } \\
\text { et al. [92] } \\
\text { Sebsadji } \\
\text { et al. [93] }\end{array}$ & $\begin{array}{l}\text { Longitudinal \& lateral accelera- } \\
\text { tion, steering angle, wheel angular } \\
\text { velocity, yaw rate }\end{array}$ & $\begin{array}{l}\text { Tire forces and road } \\
\text { grade }\end{array}$ & $\begin{array}{l}\text { They used an extended Kalman filter and Luenberger } \\
\text { observer based method on the nonlinear vehicle model to } \\
\text { estimate the forces and road grade. }\end{array}$ \\
\hline $\begin{array}{l}\text { Cheng et al. } \\
\qquad[94]\end{array}$ & $\begin{array}{l}\text { Longitudinal \& lateral accelera- } \\
\text { tion, steering angle, wheel angular } \\
\text { velocity, yaw rate }\end{array}$ & $\begin{array}{l}\text { Vehicle side slip angle, } \\
\text { lateral tire force and tire } \\
\text { road friction coefficient }\end{array}$ & $\begin{array}{l}\text { They used unscented Kalman filter based estimation } \\
\text { algorithm to estimate the vehicle's desired states and tire } \\
\text { road friction coefficient. }\end{array}$ \\
\hline $\begin{array}{c}\text { Ray } \\
{[95,96]}\end{array}$ & $\begin{array}{l}\text { Yaw and roll rate, wheel angular } \\
\text { velocity, longitudinal and lateral } \\
\text { acceleration }\end{array}$ & $\begin{array}{l}\text { Slip ratio, slip angle, } \\
\text { wheel velocity, normal } \\
\text { force at each wheel, } \\
\text { longitudinal and lateral } \\
\text { force }\end{array}$ & $\begin{array}{l}\text { They used a nine degree of freedom model, which is a } \\
\text { four-wheel model with vehicle roll dynamic along with } \\
\text { extended Kalman filter to estimate the desired states. }\end{array}$ \\
\hline $\begin{array}{l}\text { Jin and Yin } \\
{[97]}\end{array}$ & $\begin{array}{l}\text { Longitudinal \& lateral accelera- } \\
\text { tion, steering angle, wheel angular } \\
\text { velocity, yaw \& roll rate }\end{array}$ & $\begin{array}{l}\text { Tire forces for all wheels, } \\
\text { roll angle, yaw \& roll } \\
\text { rate, velocity of CG }\end{array}$ & $\begin{array}{l}\text { They proposed two extended and unscented Kalman filter } \\
\text { based observers which used four-wheel model with the } \\
\text { roll vehicle model to estimate the tire forces and other } \\
\text { vehicle states }\end{array}$ \\
\hline $\begin{array}{l}\text { Rajamani } \\
\text { et al. [98] }\end{array}$ & $\begin{array}{l}\text { Longitudinal \& lateral accelera- } \\
\text { tion, steering angle, wheel angular } \\
\text { velocity, yaw \& roll rate }\end{array}$ & $\begin{array}{l}\text { The tire forces, longitu- } \\
\text { dinal and lateral vehicle } \\
\text { velocities, yaw and roll } \\
\text { angle }\end{array}$ & $\begin{array}{l}\text { They used extended Kalman filter approach with 8DOF } \\
\text { model (four-wheel model with roll vehicle dynamic model) } \\
\text { to estimate the tire forces and other vehicle's states. }\end{array}$ \\
\hline
\end{tabular}

Many studies have used this vehicle model along with some estimation algorithms to estimate the lateral vehicle states, friction force and/or coefficient. Table 4 summarizes some of the research which have used bicycle model in their algorithms.
The most popular vehicle models, which are widely used in friction estimation studies, are introduced in this section; Table 5 reviews these vehicle dynamic models, their common measured states and the states which are usually estimated with these models as a 


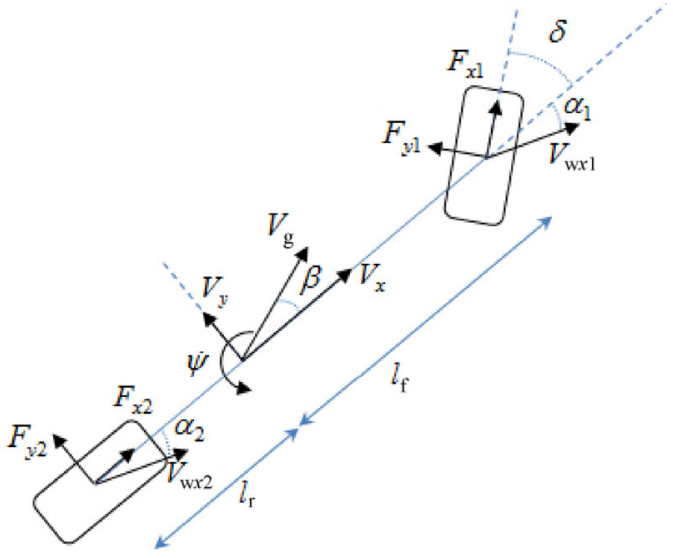

Fig. 11 The schematic of the bicycle model. summary of dynamic wheel/vehicle based approaches. The tire model based algorithms are introduced next.

\subsection{Tire model based}

Tire models generally express the relationship between tire forces and moments with slip ratio/slip angle, which have been used in various studies to estimate the friction forces and friction coefficient. It is assumed that the tire forces and moment, also slip ratio and/or slip angle are available (or can be estimated) then by comparing the force/moment-slip data with different tire models, the model parameters and friction

Table 4 Some studies which have used bicycle model.

\begin{tabular}{|c|c|c|c|}
\hline Authors & Measured states & Estimated states & Method \\
\hline $\begin{array}{l}\text { Baffet et al. }[99,100] \\
\text { Zhang et al. }[101]\end{array}$ & $\begin{array}{l}\text { Yaw rate, longitudinal \& } \\
\text { lateral acceleration, steering } \\
\text { angle }\end{array}$ & $\begin{array}{l}\text { Tire forces, vehicle side slip } \\
\text { angel }\end{array}$ & $\begin{array}{l}\text { They used sliding mode observer to estimate tire } \\
\text { road forces, then using and extended Kalman filter } \\
\text { they estimated the cornering stiffness and side-slip } \\
\text { angle. }\end{array}$ \\
\hline Baffet et al. [81] & $\begin{array}{l}\text { Yaw rate, longitudinal \& } \\
\text { lateral acceleration, vehicle } \\
\text { velocity }\end{array}$ & $\begin{array}{l}\text { Tire forces, side slip angle, } \\
\text { cornering stiffness }\end{array}$ & $\begin{array}{l}\text { First, they used extended Kalman filter to estimate } \\
\text { the tire longitudinal and lateral forces, then another } \\
\text { extended Kalman filter algorithm was used to } \\
\text { estimate the side slip angle and cornering stiffness. }\end{array}$ \\
\hline Baffet et al. [102] & $\begin{array}{l}\text { Longitudinal \& lateral } \\
\text { acceleration, steering angle, } \\
\text { wheel angular velocity, yaw } \\
\text { rate }\end{array}$ & $\begin{array}{l}\text { Lateral tire force, vehicle } \\
\text { side slip angle and yaw rate } \\
\text { and vehicle speed }\end{array}$ & $\begin{array}{l}\text { They used three different extended Kalman filter } \\
\text { based algorithm along with Burckhardt and linear } \\
\text { tire force model to estimate the tire force, yaw } \\
\text { rate, vehicle speed and side slip angle. }\end{array}$ \\
\hline Ahn [103] & $\begin{array}{l}\text { Longitudinal \& lateral } \\
\text { acceleration, steering angle, } \\
\text { wheel angular velocity, yaw } \\
\text { rate }\end{array}$ & $\begin{array}{l}\text { Lateral force, aligning } \\
\text { moment, side slip angle, } \\
\text { friction coefficient }\end{array}$ & $\begin{array}{l}\text { They used bicycle model with state estimator to } \\
\text { estimate the lateral force and aligning moment; } \\
\text { then using a sliding mode observer with brush tire } \\
\text { model, they estimated the side slip angle and friction } \\
\text { coefficient. }\end{array}$ \\
\hline Zhang et al. [104] & Yaw rate & Side slip angle and yaw rate & $\begin{array}{l}\text { They used a nonlinear observer to estimate the side } \\
\text { slip angle, its stability conditions were obtained } \\
\text { from analysis of energy to peak performance of } \\
\text { the estimation error system. }\end{array}$ \\
\hline $\begin{array}{l}\text { Zhu and Zheng [105] } \\
\text { Pan et al. [106] }\end{array}$ & $\begin{array}{l}\text { Longitudinal \& lateral } \\
\text { acceleration, steering angle, } \\
\text { wheel angular velocity }\end{array}$ & $\begin{array}{l}\text { Wheel side slip angle and } \\
\text { yaw rate }\end{array}$ & $\begin{array}{l}\text { They used unscented Kalman filter to estimate the } \\
\text { side slip angle and the yaw rate. }\end{array}$ \\
\hline Chu et al. $[107,108]$ & $\begin{array}{l}\text { Yaw rate, longitudinal \& } \\
\text { lateral acceleration, steering } \\
\text { angle, wheel angular velocity }\end{array}$ & $\begin{array}{l}\text { Vehicle longitudinal and } \\
\text { lateral velocity }\end{array}$ & $\begin{array}{l}\text { They used an adaptive unscented Kalman filter to } \\
\text { estimate the vehicle longitudinal and lateral velocity. }\end{array}$ \\
\hline Hsu et al. [109] & $\begin{array}{l}\text { Yaw rate, longitudinal \& } \\
\text { lateral acceleration, steering } \\
\text { angle }\end{array}$ & Tire slip angle & $\begin{array}{l}\text { They used a model base estimation approach; } \\
\text { utilizing pneumatic trail information they identified } \\
\text { the vehicle's lateral limits. }\end{array}$ \\
\hline Ray et al. [110] & $\begin{array}{l}\text { Yaw rate, longitudinal \& } \\
\text { lateral acceleration, the wheel } \\
\text { angular velocity }\end{array}$ & $\begin{array}{l}\text { Vehicle's longitudinal and } \\
\text { lateral speed, vertical dis- } \\
\text { placement of front, rear } \\
\text { and CG, pitch angle, the } \\
\text { longitudinal and lateral force } \\
\text { for front and rear wheels }\end{array}$ & $\begin{array}{l}\text { They used a nine degree of freedom model, which } \\
\text { is a bicycle model with a quarter-car model to } \\
\text { simulate each of the front and rear tire and } \\
\text { suspension. Using extended Kalman filter, they } \\
\text { estimated the tire forces and other states. }\end{array}$ \\
\hline Gao et al. [111] & Lateral acceleration, yaw rate & Side slip angle & $\begin{array}{l}\text { They used a high gain observer along with a } \\
\text { nonlinear tire model to estimate the vehicle side } \\
\text { slip angle. They compared the results of high gain } \\
\text { observer with the estimation results of extended } \\
\text { Kalman filter and Leunberger observer. }\end{array}$ \\
\hline
\end{tabular}


Table 5 Summary of wheel/vehicle dynamic models which are used for friction estimation.

\begin{tabular}{|c|c|c|c|}
\hline Model name & $\begin{array}{c}\text { Common } \\
\text { measured states }\end{array}$ & $\begin{array}{c}\text { Common } \\
\text { estimated states }\end{array}$ & Features \\
\hline $\begin{array}{l}\text { Wheel dynamic } \\
\text { model }\end{array}$ & $\begin{array}{l}\text { Longitudinal acceleration, } \\
\text { wheel angular velocity, drive } \\
\& \text { braking torque, rolling } \\
\text { resistance force }\end{array}$ & $\begin{array}{l}\text { Longitudinal tire force, } \\
\text { longitudinal speed, }\end{array}$ & $\begin{array}{l}\text { 1. Used to study the longitudinal dynamics of the vehicle. } \\
\text { 2. The accuracy of the estimation using this model highly } \\
\text { depends on the accuracy of the tire effective radius } \\
\text { which is used for estimation. }\end{array}$ \\
\hline 1-DOF roll model & CG's lateral acceleration & Roll angle, roll rate & $\begin{array}{l}\text { 1. Used to estimate roll dynamics of the vehicle. } \\
\text { 2. Roll stiffness and damping coefficient are assumed to } \\
\text { be constant. } \\
\text { 3. The roll axis assumed to be fixed. } \\
\text { 4. Does not need the information of cornering stiffness. } \\
\text { 5. It's not sensitive to nonlinear tire dynamics. }\end{array}$ \\
\hline Quarter car model & $\begin{array}{l}\text { Vertical acceleration of sprung } \\
\text { mass and un-sprung mass }\end{array}$ & $\begin{array}{l}\text { Tire vertical force, } \\
\text { vertical position and } \\
\text { velocity of sprung mass } \\
\text { and un-sprung mass }\end{array}$ & $\begin{array}{l}\text { 1. Mostly used to model vertical dynamics of the vehicle } \\
\text { and suspension modeling. } \\
\text { 2. Pitch and roll motion are not taken into account. } \\
\text { 3. The wheels are assumed to roll without slip and contact } \\
\text { loss. }\end{array}$ \\
\hline $\begin{array}{l}\text { Four-wheel vehicle } \\
\text { model }\end{array}$ & $\begin{array}{l}\text { Longitudinal and lateral } \\
\text { acceleration, yaw acceleration, } \\
\text { steer angle }\end{array}$ & $\begin{array}{l}\text { Tire's longitudinal and } \\
\text { lateral force, wheel hub } \\
\text { velocity of each wheel }\end{array}$ & $\begin{array}{l}\text { 1. Used to study the longitudinal and transversal vehicle } \\
\text { dynamics. } \\
\text { 2. Roll and pitch motion are ignored. } \\
\text { 3. Doesn't have a suspension. }\end{array}$ \\
\hline Bicycle model & $\begin{array}{l}\text { Lateral acceleration, yaw } \\
\text { acceleration, steer angle }\end{array}$ & $\begin{array}{l}\text { Front and rear lateral } \\
\text { tire force }\end{array}$ & $\begin{array}{l}\text { 1. Used to describe lateral dynamics of the vehicle. } \\
\text { 2. Rear steering angle assumed to be zero. } \\
\text { 3. Vertical and roll motion are ignored. }\end{array}$ \\
\hline
\end{tabular}

coefficient are estimated.

Different mathematical tire models have been developed based on model of the tire and the time behavior that can be captured (steady-state or transient) (Fig. 12) [68]; some of them which are more common for the friction estimation purpose are introduced in this article.

\subsubsection{Pacejka tire model}

Pacejka tire model (which is also called magic formula)

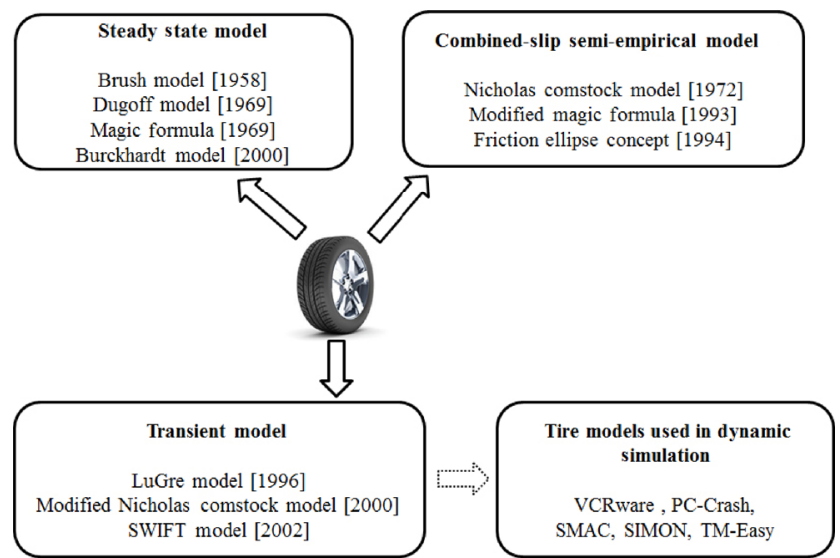

Fig. 12 Different tire models. Reproduce with permission from Ref. [68]. Copyright Singh, 2012. is a semi-empirical tire model that was introduced for the first time by Pacejka in 1992 [112]. The model uses special functions to represent the longitudinal and lateral forces and the aligning moment. The formulation of this tire model for longitudinal and lateral force and aligning moment are as follows:

$$
\begin{aligned}
& F_{x}\left(s+S_{\mathrm{h} x}\right)= \\
& D_{x} \sin \left[C_{x} \arctan \left(B_{x} s-E_{x}\left(B_{x} s-\arctan \left(B_{x} s\right)\right)\right)\right]+S_{\mathrm{v} x} \\
& F_{y}\left(\alpha+S_{\mathrm{h} y}\right)= \\
& D_{y} \sin \left[C_{y} \arctan \left(B_{y} \alpha-E_{y}\left(B_{y} \alpha-\arctan \left(B_{y} \alpha\right)\right)\right)\right]+S_{\mathrm{v} y} \\
& M_{z}\left(\alpha+S_{\mathrm{h} z}\right)= \\
& D_{z} \sin \left[C_{z} \arctan \left(B_{z} \alpha-E_{z}\left(B_{z} \alpha-\arctan \left(B_{z} \alpha\right)\right)\right)\right]+S_{\mathrm{v} z}
\end{aligned}
$$

where $s$ is the slip ratio, $\alpha$ is the side slip angle and $F_{x}, F_{y}, M_{z}$ are the longitudinal force, lateral force and aligning moment respectively. The meaning of other parameters $\left(B, C, D, S_{\mathrm{h}}, S_{\mathrm{v}}\right)$ are shown in Fig. 13.

In the newer version of the magic formula, the camber angle, cornering stiffness, and load variation also transient properties of the tire are also taken into account [113]. Magic formula has been widely used in literature for vehicle states and tire friction 


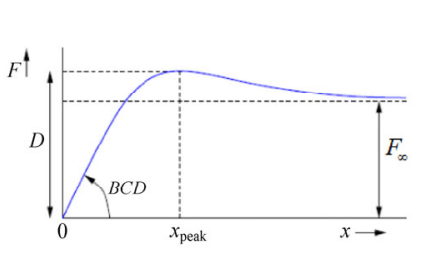

$$
\begin{aligned}
& D: \text { Peak value } \\
& C: \text { The limit value when } \quad x \rightarrow \infty \\
& C=2-\frac{2}{\pi} \arctan \left(\begin{array}{c}
F_{\infty} \\
D
\end{array}\right) \quad C \geqslant 1 \\
& B \times C \times D: \text { The slope near the origin } \\
& B, E \& C: \text { The location of the peak } \\
& E=\frac{B x_{\text {peak }}-\tan \left(\frac{\pi}{2 C}\right)}{B x_{\text {peak }}-\arctan \left(B x_{\text {peak }}\right)} \quad E \geqslant 1
\end{aligned}
$$

Fig. 13 Magic Formula's parameters.

estimation [112, 114, 115]. van Oosten et al. [116] clarified the determination of Magic Formula parameters from the experimental data, and discussed all the difficulties involved. Kim et al. [117] used the traditional concept of friction to formulate the friction; they assumed that the coefficients of Magic Formula are known. Using an instrumented vehicle they estimated the forces on each wheel with the help of Magic Formula. Then they estimated the longitudinal and lateral friction coefficients. Yi et al. [118] used an observer-based algorithm, in which the Magic Formula with known parameters was used for the longitudinal force, to estimate the tire road friction coefficient. First, they used a sliding mode observer (angular velocity of the wheel was measured) to estimate the vehicle states, then using a recursive least square algorithm, they estimated the tire road friction coefficient. Jayachandran et al. [119] developed a fuzzy logic based algorithm to estimate the value of longitudinal and lateral forces, also aligning moment based on slip ratio and slip angle. They used Magic Formula with known coefficients to calculate the tire forces and moment based on different slip values; then they defined a fuzzy membership function between the inputs (slip ratio, slip angle) and outputs (tire forces, aligning moment) of fuzzy-logic algorithm based on the calculated values.

\subsubsection{Dugoff tire model}

Dugoff tire model is a physical model, which was introduced by Dugoff et al. in 1969 [120]. In this model, a uniform vertical pressure distribution is assumed on the tire contact patch. In its simplest form, Dugoff model expresses the relation between longitudinal and lateral force and the slip as a function of two parameters; the tire stiffness $\left(C_{x}, C_{y}\right)$, which explains the slope of force-slip curve in low slip region and the tire-road friction coefficient $(\mu)$ that describes its curvature and peak value. The Dugoff model is formulated as follows:

$$
\begin{aligned}
& F_{x}=C_{x} \frac{s}{1+s} f(\lambda) \\
& F_{y}=C_{y} \frac{\tan (\alpha)}{1+s} f(\lambda) \\
& \lambda=\frac{\mu F_{z}(1+s)}{2 \sqrt{\left(C_{x} s\right)^{2}+\left(C_{y} \tan \alpha\right)^{2}}} \\
& f(\lambda)=\begin{array}{ll}
(2-\lambda) \lambda \quad & \lambda<1 \\
1 \quad & \lambda \geqslant 1
\end{array}
\end{aligned}
$$

where $C_{x}, C_{y}$ are the slopes of the longitudinal forceslip ratio and lateral force-slip angel in the low slip values (linear part of the curve respectively). In the following context, some of the studies that have used the Dugoff tire model in order to estimate the friction or related parameters are introduced. Ghandour et al. [89] developed an algorithm, using Dugoff to simulate the lateral force, to estimate the lateral friction coefficient. First, they developed an estimation algorithm to obtain the lateral force and slip angle. Then, they estimated the friction coefficient utilizing nonlinear method of optimization to minimize the error between estimated lateral force and lateral force provided by Dugoff model. In another study, a new algebraic filtering technique was used by Villagra et al. [121] to estimate the longitudinal and lateral force and slip ratio, then they used a weighted Dugoff model to estimate the friction coefficient, for instance for the longitudinal direction simplifying the Dugoff equation gives:

$$
\mu_{x-\max }^{2} F_{z}^{2}-2 \mu_{x-\max }\left|C_{x} \tau\right| F_{z}+\left|C_{x} \tau\right| F_{z}=0
$$

where in this equation $\tau=\frac{s}{1+s}$. The solution for this equation is expressed as:

$$
\mu_{x-\max }=\frac{\left(\left|C_{x} \tau\right| \pm \sqrt{C_{x} \tau\left(C_{x} \tau-F_{x}\right)}\right)}{F_{z}}
$$

Comparing the behavior of Dugoff model with Pacejka's model, the maximum friction coefficient is obtained as follows:

$$
\begin{aligned}
\mu_{x-\max }^{D}\left(t_{\mathrm{k}}\right) & =\frac{\alpha_{1}}{F_{z}(t)}\left(\left|C_{x} \tau\left(t_{\mathrm{k}}\right)\right|-\sqrt{C_{x} \tau\left(t_{\mathrm{k}}\right)\left(C_{x} \tau\left(t_{\mathrm{k}}\right)-F_{x}\left(t_{\mathrm{k}}\right)\right)}\right) \\
\lambda\left(t_{\mathrm{k}}\right) & <1 \\
\mu_{x-\max }^{D}\left(t_{\mathrm{k}}\right) & =\mu_{x-\max }^{D}\left(t_{\mathrm{k}}-1\right) \quad \lambda\left(t_{\mathrm{k}}\right) \geqslant 1
\end{aligned}
$$


where $\alpha_{1}$ is a weighting factor. Nilanjan et al. [122] proposed a sliding mode observer along with modified Dugoff model to estimate the longitudinal velocity and friction coefficient; the only measured state was wheel angular velocity. Doumiati et al. [86] proposed a real time algorithm to estimate the tire-road lateral forces and side slip angle using two estimation algorithms of extended and unscented Kalman filter, in which the lateral force was modeled using Dugoff model. Four-wheel vehicle model was used as the dynamical model of the system, and the measured states were longitudinal and lateral acceleration, yaw and roll rate, left and right suspension deflection and the angular velocity of each wheel.

\subsubsection{Brush tire model}

In this model, it is assumed that the surface area which is in contact with the road can be modeled as infinitesimal bristles. As it is shown in Fig. 14, the contact patch area is partitioned into two regions [123]: adhesion and sliding. In the first region, the bristles transfer the force by mechanical adhesion and in the second region the slide of the bristles on the road results in friction force; the vertical pressure distribution is assumed to be parabolic.

The brush tire model can be divided into 3 cases: pure side-slip, pure longitudinal slip, and combined slip problem.

\subsubsection{Pure side-slip}

Figure 15 demonstrates the schematic of the contact patch in small and large side slip conditions. For the pure side slip problem, the formulation of brush tire model for low slip angle values is as follows [124]:

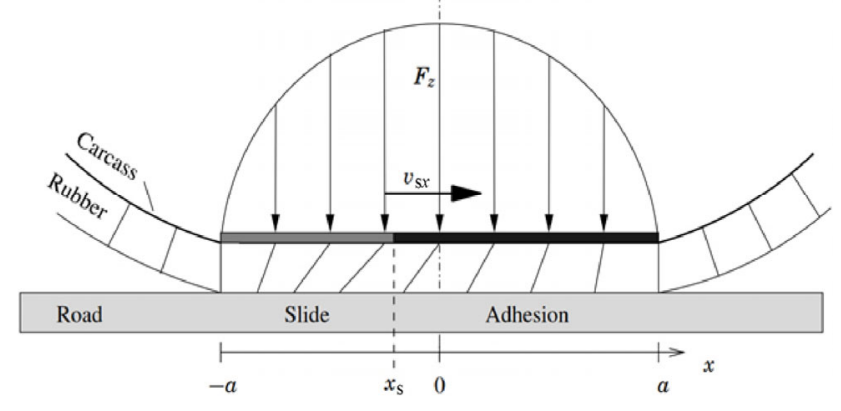

Fig. 14 The schematic of adhesion and sliding regions in the contact patch [123].
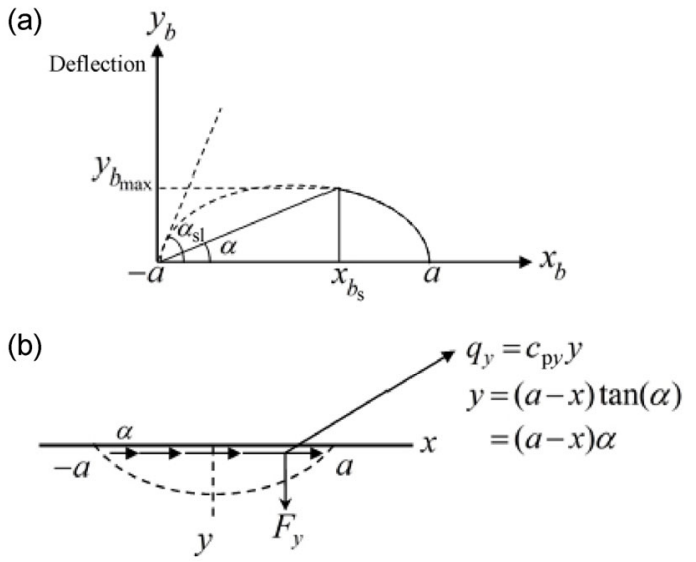

Fig. 15 Schematic of the contact patch: (a) load distribution and (b) deflection.

$$
\begin{aligned}
& F_{y}=C_{F \alpha} \alpha \\
& M_{z}=\frac{a}{3} F_{y}
\end{aligned}
$$

where $a$ is the contact patch length and $C_{F \alpha}$ is the cornering stiffness. For large side slip values the equations are expressed as [125]:

$$
\begin{aligned}
F_{y}= & 3 \mu F_{z} \frac{\tan (\alpha)}{\tan \left(\alpha_{\mathrm{sl}}\right)}\left(1-\left|\frac{\tan (\alpha)}{\tan \left(\alpha_{\mathrm{sl}}\right)}\right|+\frac{1}{3} \frac{\tan ^{2}(\alpha)}{\tan ^{2}\left(\alpha_{\mathrm{sl}}\right)}\right) \\
M_{z} & =-\mu F_{z} a \frac{\tan (\alpha)}{\tan \left(\alpha_{\mathrm{sl}}\right)}\left\{1-3\left|\frac{\tan (\alpha)}{\tan \left(\alpha_{\mathrm{sl}}\right)}\right|+3 \frac{\tan ^{2}(\alpha)}{\tan ^{2}\left(\alpha_{\mathrm{sl}}\right)}\right. \\
& \left.-\left|\frac{\tan (\alpha)}{\tan \left(\alpha_{\mathrm{sl}}\right)}\right|^{3}\right\} \\
\mu= & \frac{2 c_{\mathrm{py}} a^{2}}{3 F_{z}} \tan \left(\alpha_{\mathrm{sl}}\right)
\end{aligned}
$$

where $c_{\mathrm{p} y}$ is the lateral stiffness of the tread element per unit length of the contact area, $\alpha$ is the side-slip angle and $\alpha_{\text {sl }}$ is shown in Fig. 15(b).

\subsubsection{Pure longitudinal slip}

With the assumption of pure longitudinal slip, parabolic vertical load distribution, and constant friction level, the longitudinal force is expressed as follows [126]:

$$
F_{x}=\begin{array}{ll}
-C_{x} s+\frac{C_{x}^{2} s|s|}{3 \mu F_{z}}-\frac{C_{x}^{3} s^{3}}{27 \mu^{2} F_{z}^{2}} & s<s^{\circ} \\
\mu F_{z} \operatorname{sgn}(s) & \text { otherwise }
\end{array}
$$

where $s^{\circ}=3 \frac{\mu F_{z}}{C_{x}}$ and $s$ is the slip ratio. 


\subsubsection{Combined slip}

For the case that both longitudinal and lateral slip are available, to simplify the problem it is assumed that the normal force distribution is parabolic, and the longitudinal and lateral stiffness of the tread elements, and the longitudinal and lateral friction coefficients are equal [124].

$$
\begin{aligned}
& c_{\mathrm{p}}=c_{\mathrm{p} x}=c_{\mathrm{p} y} \\
& \mu=\mu_{x}=\mu_{y}
\end{aligned}
$$

The theoretical slips are defined as follow:

$$
\begin{aligned}
& \sigma_{x}=\frac{s}{1+s} \\
& \sigma_{y}=\frac{\tan \alpha}{1+s} \\
& \sigma=\sqrt{\sigma_{x}^{2}+\sigma_{y}^{2}}
\end{aligned}
$$

The magnitude of total force is expressed as follows:

$$
\begin{array}{ll}
F=\begin{array}{ll}
\mu F_{z}\left\{3 \theta \sigma-3(\theta \sigma)^{2}+(\theta \sigma)^{3}\right\} & \sigma \leqslant \sigma_{\mathrm{sl}} \\
\mu F_{z} & \sigma \geqslant \sigma_{\mathrm{sl}}
\end{array} \\
\theta=\frac{2}{3} \frac{c_{p} a^{2}}{\mu F_{z}} &
\end{array}
$$

where $\sigma_{\mathrm{sl}}=\frac{1}{\theta}$ and $a$ is half of the contact patch length as it is shown in Fig. 14. Several studies have used different forms of brush model in their friction estimation algorithms, some of these studies are summarized in Table 6.

\subsubsection{LuGre tire model}

LuGre tire model is a physics based dynamic tire model, which was first introduced by de Wit et al. in 1995. The surfaces are assumed to be in contact through elastic bristles. This is shown in Fig. 16 [130].

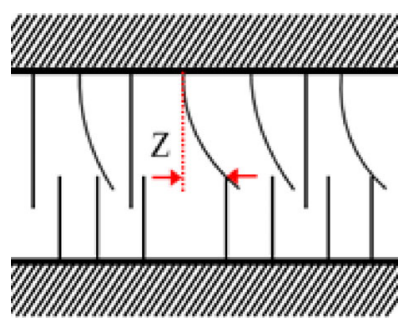

Fig. 16 LuGre model-contact surfaces.
The average deflection of the bristles in the lumped LuGre model (which is presented by $z$ ) is expressed as [130]

$$
\begin{aligned}
& \frac{\mathrm{d} z}{\mathrm{~d} t}=v-\frac{|v|}{g(v)} z \\
& F=\sigma_{0} z+\sigma_{1} \frac{\mathrm{d} z}{\mathrm{~d} t}+\sigma_{2} v \\
& \sigma_{0} g(v)=F_{\mathrm{c}}+\left(F_{\mathrm{s}}-F_{\mathrm{c}}\right) \mathrm{e}^{-\left(\frac{v}{v_{\mathrm{s}}}\right)^{2}}
\end{aligned}
$$

where $v$ is the relative velocity between the two surfaces, $v_{\mathrm{s}}$ is Stribeck velocity, $F_{\mathrm{c}}$ is the Coulomb friction level, $F_{\mathrm{s}}$ is the level of stiction force, $\sigma_{0}$ is rubber stiffness, $\sigma_{1}$ is rubber damping coefficient, and $\sigma_{2}$ is the viscous relative damping. In the distributed LuGre Model, an area of contact is assumed between the tire and the road, which formulates the friction force as follows [131]:

$$
\begin{aligned}
& F(s)=\operatorname{sgn}\left(v_{\mathrm{r}}\right) F_{\mathrm{n}} g(s)\left(1+\gamma \frac{g(s)}{\sigma_{0} L|s|}\left(e^{-\frac{\sigma_{\mathrm{L}} L / s \mid}{g(s)}}-1\right)\right)+F_{\mathrm{n}} \sigma_{2} r \omega s \\
& \gamma=1-\sigma_{1}\left|v_{\mathrm{r}}\right| / g(s) \\
& g(s)=\mu_{\mathrm{c}}+\left(\mu_{\mathrm{s}}+\mu_{\mathrm{c}}\right) \mathrm{e}^{-\left|r \omega s / v_{s}\right|^{\frac{1}{2}}}
\end{aligned}
$$

where $F_{\mathrm{n}}$ is the normal load, $L$ is the contact patch length and $v_{\mathrm{r}}=(r \omega-v)$ is the relative velocity. Several studies have used LuGre model to estimate the friction force or friction coefficient. de-Wit et al. [62] used a single wheel dynamic model with lumped LuGre friction model and introduced a new parameter which represented the road change. Using the measured data of angular velocity of the wheel, they designed an online observer for the vehicle longitudinal velocity and the road condition parameters $[62,60]$. Alvarez et al. [132] also used the same approach to design a tire friction model for emergency braking control. They also used a single wheel dynamic model along with lumped LuGre formulation for the force. Utilizing the measured data of wheel angular speed, the internal state of the LuGre model $(z)$, the longitudinal and relative velocity $\left(v_{\mathrm{r}}\right)$ are estimated. Chen et al. used a bicycle model and propose the following observer in order to estimate the internal states of LuGre tire 
Table 6 Sample studies in which brush model have been used.

\begin{tabular}{ll}
\hline Author's name & \multicolumn{1}{c}{ Method which was used } \\
\hline Svendenius [120] & $\begin{array}{l}\text { Developed a brush based tire model to derive the tire forces and moment at combined slip, from scaling the forces } \\
\text { given by empirical pure slip }\left(\sigma_{x}, \sigma_{y}, \gamma\right) \text {, at certain pure slips: } \\
(\end{array}$ \\
& $\left.\sigma_{0 x}\left(\sigma_{x}, \sigma_{y}, \gamma\right), \sigma_{0 y}\left(\sigma_{x}, \sigma_{y}, \gamma\right)\right)=G_{\mathrm{ax}} F_{0 x}\left(\sigma_{0 x \mathrm{a}}\right)+G_{\mathrm{sx}} F_{0 x}\left(\sigma_{0 x \mathrm{~s}}\right)$ \\
& $F_{y}\left(\sigma_{x}, \sigma_{y}, \gamma\right)=G_{\mathrm{ay}} F_{0 y}\left(\sigma_{0 y \mathrm{a}}\right)+G_{\mathrm{sy}} F_{0 y}\left(\sigma_{0 y \mathrm{~s}}\right)+G_{\mathrm{camy}} F_{0 \mathrm{cam}}(\gamma)$ \\
& $M_{z}\left(\sigma_{x}, \sigma_{y}, \gamma\right)=G_{\mathrm{ay}} F_{0 y}\left(\sigma_{0 y \mathrm{a}}\right)+G_{\mathrm{m} z} M_{0 z}\left(\sigma_{0 z}\right)+G_{\mathrm{camz}} F_{0 \mathrm{cam}}(\gamma)$ \\
& where $F_{0 x}, F_{0 y}$ are from the empirical pure slip model, $F_{0 \mathrm{cam}}$ is the empirical pure cambering model, the normal \\
& load assumed to be parabolic distributed and the scale factors $G_{i j}$ are derived from the analytical expressions of \\
& brush model.
\end{tabular}

Andersson et al. They used an extended brush model in combined with slip mode to estimate the lateral friction. They used

[127] self-aligning torque as the estimation basis, instead of lateral force (because it shows more nonlinear behavior at low slip angle) to broaden the operation area of lateral estimator.

Nishihara et al. They used brush model to describe the essential relation between the tire forces and aligning moment and the grip

[128] margin, which is defined as the residual tire forces normalized by the radius of friction circle:

$\varepsilon=1-\frac{\sqrt{F_{x}^{2}+F_{y}^{2}}}{\mu F_{z}}$

It is assumed that the lateral force, aligning moment and the contact patch length are available, the friction coefficient is determined as:

$$
\begin{aligned}
& \mu=\frac{\sqrt{F_{x}^{2}+F_{y}^{2}}}{(1-\varepsilon) F_{z}} \\
& \varepsilon=\frac{1}{729}\left[\frac{2^{1 / 3}\left(9 \xi+\xi^{2}\right)}{W(\xi)}+\xi+\frac{W(\xi)}{2^{1 / 3}}\right]^{3} \quad \xi=\frac{6 M_{z}}{F_{y} a} \\
& W(\xi)=\left(2 \xi^{3}+27 \xi^{2}+243 \xi+27 \xi \sqrt{\xi^{2}+14 \xi+81}\right)^{\frac{1}{3}}
\end{aligned}
$$

Matilainen and They estimate the friction potential during the lateral driving maneuver without any knowledge of tire stiffness Tuoronen [41] based on brush tire model. Having the tire forces (estimated using bicycle model) the friction potential is calculated as follows:

$$
\begin{aligned}
& \mu_{\text {potential }}\left(F_{y} / F_{z}, \lambda\right)=-\frac{F_{y} / F_{z}}{\left(\lambda^{3}-1\right)} \text { where } \lambda \text { is defined as } \\
& \frac{M_{z}}{a F_{y}}=-\frac{\lambda^{3}}{\lambda^{2}+\lambda+1}
\end{aligned}
$$

Yamazaki et al. They used brush tire model (with the assumption of parabolic distributed normal load) to estimate the longitudinal

[129] friction coefficient for two cases of partially sliding and pure sliding. For the case of partially sliding $\mu$ can be determined from:

$$
9 \mu_{x}^{2} F_{z}^{2}\left(F_{x}-C_{x} s\right)+3 \mu_{x} F_{z} C_{x}^{2} s^{2}-C_{x}^{3} s^{3} / 3=0
$$

And for pure sliding mode:

$$
\mu_{x}=\frac{F_{x}}{F_{z}}
$$

model [126].

$$
\dot{\hat{z}}=v_{\mathrm{r}}-\bar{\theta} \sigma_{0} f\left(v_{\mathrm{r}}\right) \hat{z}+K\left(\mu_{i}-\hat{\mu}\right)
$$

With $\hat{\mu}=\sigma_{0} \hat{z}-\bar{\theta} \sigma_{0} \sigma_{1} f\left(v_{\mathrm{r}}\right) \hat{z}+\left(\sigma_{1}+\sigma_{2}\right) v_{\mathrm{r}}$ and $\bar{\theta}$ is a constant, ensure that $\lim _{t \rightarrow \infty} \hat{z}=z$ for each tire,
$K=1 / \sigma_{1}$ and $\mu_{i}=\frac{F_{x i}}{F_{\mathrm{n} i}}$ which is calculated form dynamical equation of the motion for each wheel. Knowing the parameters of the LuGre tire model, the friction coefficient is estimated using a recursive least square algorithm. In another study, Alvarez et al. [132] 
developed an adaptive friction estimation algorithm based on LuGre tire model. They used a quarter car model in which the forces were modeled using LuGre formulation and estimated the vehicle velocity and internal parameters of LuGre model using sliding mode observer. The measured states were the wheel angular velocity and the longitudinal acceleration. Matusko et al. [133] have used lumped LuGre model to explain the dynamics of friction force. They used a single wheel dynamic model along with LuGre tire model to estimate the friction force. A Neural Network (NN) algorithm is also used to compensate the uncertainties in the tire friction model. They used Lyapanov Direct Method to adapt the parameters of the NN algorithm. In some studies, LuGre tire model has been used as the basis to develop new dynamic models. Cleays et al. [61] have developed a LuGre based tire model, which describes the longitudinal and lateral forces and the aligning moment with a set of first order differential equations suitable for use in traction and ABS braking controllers.

In this section, four tire models which have been used more than other tire models were discussed; the overall specifications of these models are summarized in Table 7.

The slip-slop based algorithm which is another member of the model based approaches are discussed in following section.

\subsection{The slip-slope method}

This method is based on the hypothesis that the low slip-low $\mu$ part of the slip curve (during normal driving condition) can be used to estimate the maximum tire-road friction. This has been claimed in several studies [22, 63, 66, 134-136]. Slip is defined as the relative velocity between the tire and the road [77].

$$
\begin{array}{ll}
s=\frac{\omega_{\mathrm{w}} r_{\mathrm{w}}-v_{\mathrm{w}}}{v_{\mathrm{w}}} & \text { during braking } \\
s=\frac{\omega_{\mathrm{w}} r_{\mathrm{w}}-v_{\mathrm{w}}}{\omega_{\mathrm{w}} r_{\mathrm{w}}} & \text { during accelerating }
\end{array}
$$

where $r_{\mathrm{w}}$ is the effective rolling radius of the wheel, $\omega_{\mathrm{w}}, v_{\mathrm{w}}$ are the angular and circumferential velocity of the wheel respectively. It is assumed that the values of slip ratio and normalized traction force $\left(\frac{F_{x}}{F_{\mathrm{N}}}\right)$ are available (through ABS sensor or other methods). Using different regression models on the linear region of $\mu$-slippage curve, the maximum value of friction coefficient is estimated. In other studies a linear model has been used to fit the data. Gustafsson [77] suggested the following regression model to be used for $\mu$-slippage curve:

$$
\begin{aligned}
& \mu=k s-k \delta \\
& \delta=\left.s\right|_{\mu \approx 0}, k=\left.\frac{\mathrm{d} \mu}{\mathrm{d} x}\right|_{\mu \approx 0}
\end{aligned}
$$

\begin{tabular}{|c|c|c|c|}
\hline Year & Name & properties & Feature \\
\hline 1958 & Brush model & Physical based & $\begin{array}{l}\text { 1. It's a general model which is physically derived from variants of brush model. } \\
\text { 2. Describe the forces in: pure accelerating/braking, pure cornering and combined mode. } \\
\text { 3. The friction assumed to be constant. } \\
\text { 4. Partition the contact patch to two parts: adhesion and sliding regions. } \\
\text { 5. The effect of carcass deformation is neglected. } \\
\text { 6. The elements are assumed to be linearly elastic. }\end{array}$ \\
\hline 1969 & Dugoff model & Physical based & $\begin{array}{l}\text { 1. It's a velocity independent tire model. } \\
\text { 2. Use two constants: longitudinal and lateral stiffness }\left(C_{x}, C_{y}\right) \text { to describe the tire behavior. } \\
\text { 3. Describe the forces in: pure accelerating/braking, pure cornering and combined mode. } \\
\text { 4. Consider a coupled relationship between longitudinal and lateral tire force. }\end{array}$ \\
\hline 1987 & Magic formula & Semi-Empirical & $\begin{array}{l}\text { 1. Can accurately fit to measured data. } \\
\text { 2. Describe the steady state tire behavior. } \\
\text { 3. Has lots of revised version. } \\
\text { 4. It's physically meaningful. } \\
\text { 5. Easy to use. }\end{array}$ \\
\hline 1995 & LuGre model & Physical based & $\begin{array}{l}\text { 1. It's a velocity dependent tire model. } \\
\text { 2. Can capture the Stribeck }{ }^{*} \text { effect. } \\
\text { 3. Can describe the hysteresis loop, pre-sliding displacement, ... } \\
\text { 4. Has two versions of lumped mass and distributed mass. }\end{array}$ \\
\hline
\end{tabular}

Table 7 Specifications of discussed tire models. 
Then a Kalman filter supported by change detection algorithm is used to accurately estimate the so-called slip slope. Germann et al. [137] used a second order polynomial to express the $\mu$-slip relation as follows:

$$
\mu=a_{0}+a_{1} s+a_{2} s^{2}
$$

where the coefficients of this polynomial are calculated from $\mu$-slip curve, they showed that this model works well for the slip range of less than 0.3 (30\%). Müller et al. [138] used the $\mu$-slip data collected from a braking maneuver and proposed the following regression model:

$$
\mu=\mu^{\prime} \frac{s}{c_{1} s^{2}+c_{2} s+1}
$$

where $\mu^{\prime}$ is the slope of $\mu$-slip curve and $c_{1}, c_{2}$ are calculated using a least square algorithm. Several other studies have used similar algorithms to obtain the maximum friction coefficient from the slip-slope curve $[135,139]$. Lee et al. [140] used a wheel dynamic model to estimate the longitudinal force and wheel slip; then using recursive least square, they calculated the slope of $\mu$-slip curve.

\subsection{Other friction models}

Although the main focus of this study is to introduce the most popular approaches, which are widely used in tire-road friction estimation, there are many valuable studies that have tried to develop a new friction model. Some of these approaches are discussed in this section.

The first model which is discussed is Persson's friction model. Persson [141,142] proposed a physicsbased multiscale friction model based on the nature of the substrate surface roughness and viscoelastic behavior of the rubber at different length scale from micro to macro scale. He assumed that the friction force is directly related to internal friction of the rubber which occurs due to oscillating forces on the rubber surface at different magnifications. He obtained the hysteresis friction as a function of sliding velocity $v_{\mathrm{s}}$ and wave vector $q$ at different length scales as:

$$
\mu_{\mathrm{H}}\left(v_{s}\right)=\frac{1}{2} \int_{q_{0}}^{q_{1}} \mathrm{~d} q q^{3} C(q) P(q) \int_{0}^{2 \pi} \mathrm{d} \phi \cos \phi \operatorname{Im} \frac{E\left(\omega, T_{q}\right)}{\left(1-\vartheta^{2}\right) \sigma_{0}}
$$

where $\vartheta$ and $\sigma_{0}$ are Poisson ratio and the nominal pressure of the tire, respectively. The Young modulus $E$ is a function of loading frequency $\left(\omega=q v_{s} \cos \phi\right)$ applied by multiscale asperities of the road surface and flash temperature $T_{q}$ at different length scale. $C(q)$ is the roughness power spectrum of the surface and $P(q)$ is the ratio of the tire-substrate apparent contact area to the nominal contact area, both as a function of spatial frequency. The lower limit of the integral is a reference wave vector at the lowest magnification $q_{0}$ and the upper limit is the large wave vector cut-off $q_{1}$ which is related to material properties of tire when there is no contamination on the substrate surface, otherwise it is related to the size of contamination particles.

Later, Lorenz et al. [143] added a semi-empirical adhesion model of friction coefficient to Persson's hysteresis model to find the total friction at low velocities.

$$
\mu_{\mathrm{Ad}}\left(v_{s}\right)=\frac{\tau_{\mathrm{f} 0}}{\sigma_{0} P\left(q_{1}\right)} \exp \left(-c\left[\log \left(\frac{v_{s}}{v_{0}}\right)\right]^{2}\right)
$$

where $c, v_{0}$, and $\tau_{\mathrm{f} 0}$ are empirical constants.

Klüppel and his colleagues [144, 145] proposed a friction theory similar to Persson's. Their approach also relates the rubber friction on rough surfaces to the dissipated energy of the rubber during sliding stochastic excitations on a broad frequency scale. Instead of wave vector (spatial frequency), they worked in temporal frequency domain $\omega=q v_{s}$ and separated the effect of macro and micro texture using following model:

$$
\begin{aligned}
\mu_{\mathrm{H}}\left(v_{s}\right)= & \frac{1}{2} \frac{\langle\delta\rangle}{\sigma_{0} v_{s}}\left\{\int_{\omega_{\min }}^{\omega_{2}} \mathrm{~d} \omega \omega \operatorname{Im}(E(\omega)) S_{1}(\omega)\right. \\
& \left.+\int_{\omega_{2}}^{\omega_{\max }} \mathrm{d} \omega \omega \operatorname{Im}(E(\omega)) S_{2}(\omega)\right\}
\end{aligned}
$$

where $\langle\delta\rangle$ is the excited layer thickness which is proportional to the mean penetration depth of rubber. $S_{1}(\omega)$ and $S_{2}(\omega)$ are the power spectrum densities in frequency space for the macrotexture and the microtexture, respectively. In contrast to Persson's model, which is fully 3D, Klüppel model takes into account the 3D profile of surface roughness in some average way and gives different numerical results. 
Later, Motamedi et al. [146] combined the two-scaling regimes approach (macro and micro) of Klüppel [144] with theoretical model of Persson [141] to compare the physics-based theory with indoor experimental results. He found fair agreements between theory and experiments. He also discussed the possible factors involved in experiments, which is not considered in the theatrical model such effect of rubber wear and wear particles on rubber friction.

Since all these physic-based theories developed based on mechanisms of a sliding rubber block, they cannot solely provide a complete description of tire friction. Ignatiev and Wies [147] demonstrated a hierarchy of approaches on vehicle, tire, and rubber-road contact scales should be used to obtain a good estimation of tire-road friction. They also reviewed modeling, simulation and experimental approaches for investigations of tire-road interactions in their article.

Henry et al. [148, 149] developed a friction model (also known as Pennsylvania State friction model) that uses an exponential form to express the relation between the friction and slip in steady state condition. A modified version of Pennsylvania State friction model is Permanent International Association of Road Congresses or the World Road Association (PIARC) friction model [149], which is as follows:

$$
\mathrm{SN}_{2}=\mathrm{SN}_{1} \mathrm{e}^{\frac{-(\mathrm{sv})_{2}-(\mathrm{sv})_{1}}{\mathrm{~S}_{\mathrm{p}}}}
$$

where $\mathrm{SN}_{1}, \mathrm{SN}_{2}$ are the skid numbers measured at the slip speed of $(\mathrm{sv})_{1}$ and $(\mathrm{sv})_{2}$ respectively and $S_{\mathrm{p}}$ is the speed constant related to the macrotexture of the pavement that is determined using following equation [148]:

$$
S_{\mathrm{p}}=14.2+89.7 \mathrm{MPD}
$$

where MPD stands for the mean profile depth of the pavement. The most important advantage of both of these friction models (Penn State model and PIARC model) is that they included the pavement macrotexture properties along with the slip speed in the friction model.

\section{Conclusions}

Sudden change in the pavement friction, caused by change in weather condition (rain, snow, etc.) plays one of the most important roles in car crashes. Unawareness of the driver about the pavement friction change and malfunction of vehicle's stability controllers lead to fatal car accidents; therefore, friction estimation is of interest to vehicle and tire industries. Several research studies have been conducted to estimate the friction force, friction coefficient and other parameters related to tire-road friction problem.

These studies can be divided into two main categories: experiment-based and model based. In the experiment-based approaches, it is attempted to correlate the measured data to friction related parameters. While in model based approaches, a mathematical model of the problem is developed first, then based on the developed model and measured states, the friction force or other friction related parameters are estimated. The properties of each of these methods are summarized in Table 8. Two factors of accuracy and repeatability are used in this table. Different methods are ranked as low, medium and high, which demonstrates how accurate a method is to estimate the desired parameters or how a study is repeatable.

The most important shortcoming of experimentbased approaches is observed to be the repeatability. When the testing conditions have some deviations from which these algorithms were trained, their accuracy decreased dramatically. Also, for the slip slope based approach, although it is claimed in several studies that there is a direct relation between the slip slope and the maximum friction coefficient, it is observed that changing the testing conditions (tire pressure, tire temperature, etc.) will change the slope of $\mu$-slip curve in the linear region which affects the accuracy and repeatability of this method.

This literature survey introduces the development of the most popular algorithms which are widely used to estimate tire-road friction and other friction-related parameters.

Open Access: The articles published in this journal are distributed under the terms of the Creative Commons Attribution 4.0 International License (http://creativecommons.org/licenses/by/4.0/), which permits unrestricted use, distribution, and reproduction in any medium, provided you give appropriate credit 
Table 8 Summary of friction estimation approaches.

\begin{tabular}{|c|c|c|c|c|}
\hline Major category & Sub- category & Short description & Accuracy & Repeatability \\
\hline \multirow{3}{*}{ Experiment-based } & $\begin{array}{l}\text { Optical sensors } \\
\text { and camera }\end{array}$ & $\begin{array}{l}\text { Using optical sensors and cameras to detect friction } \\
\text { related surface properties. }\end{array}$ & Medium & Medium \\
\hline & $\begin{array}{l}\text { Acoustic } \\
\text { sensors }\end{array}$ & $\begin{array}{l}\text { The tire noise is used to classify the surface type } \\
\text { or surface condition and correlate it to the tire- } \\
\text { road friction. }\end{array}$ & Medium & Low \\
\hline & $\begin{array}{l}\text { Tire tread } \\
\text { sensors }\end{array}$ & $\begin{array}{l}\text { Using different sensor inside the tire to monitor } \\
\text { the interaction between tire and the road. }\end{array}$ & High & Medium \\
\hline \multirow{3}{*}{ Model-based } & $\begin{array}{l}\text { Vehicle } \\
\text { dynamic based } \\
\text { method }\end{array}$ & $\begin{array}{l}\text { Using a dynamical model of the problem and the } \\
\text { data of measured states and try to estimate the } \\
\text { unmeasured states. }\end{array}$ & High & High \\
\hline & $\begin{array}{c}\text { Tire model } \\
\text { based method }\end{array}$ & $\begin{array}{l}\text { Using a tire model, which expresses the relation } \\
\text { between slip/slip ratio and tire forces and moments } \\
\text { to estimate the friction. }\end{array}$ & High & Medium \\
\hline & $\begin{array}{c}\text { Slip-slope } \\
\text { based method }\end{array}$ & $\begin{array}{l}\text { Try to estimate value of friction coefficient in the } \\
\text { saturated part of } \mu \text {-slip curve based of the slope } \\
\text { of the curve in linear region }\end{array}$ & Medium & Low \\
\hline
\end{tabular}

to the original author(s) and the source, provide a link to the Creative Commons license, and indicate if changes were made.

\section{References}

[1] Fatality analysis reporting system. National Highway Traffic Safety Administration, 2012.

[2] Fatality analysis reporting system. National Highway Traffic Safety Administration, 2011.

[3] Fatality analysis reporting system. National Highway Traffic Safety Administration, 2010.

[4] Connelly L B, Supangan R. The economic costs of road traffic crashes: Australia, states and territories. Accident Analysis \& Prevention 38(6): 1087-1093 (2006)

[5] Andreassen D. Preliminary costs for accident-types. (1992)

[6] Najafi S, Flintsch G W, Khaleghian S. Fuzzy logic inferencebased Pavement Friction Management and real-time slippery warning systems: A proof of concept study. Accident Analysis \& Prevention 90: 41-49 (2016)

[7] Najafi S, Flintsch G W, Khaleghian S. Pavement friction management-artificial neural network approach. International Journal of Pavement Engineering: 1-11 (2016)

[8] Pisano P A, Goodwin L C, Rossetti M A. US highway crashes in adverse road weather conditions. In 24th Conference on International Interactive Information and Processing Systems for Meteorology, Oceanography and Hydrology, New Orleans, LA, 2008.
[9] Andrey J. Long-term trends in weather-related crash risks. Journal of Transport Geography 18(2): 247-258 (2010)

[10] Lamm R, Choueiri E M, Mailaender T. Comparison of operating speeds on dry and wet pavements of two-lane rural highways. Transportation Research Record 1280(8): 199-207 (1990)

[11] Zhang L, Prevedouros P. Motorist perceptions on the impact of rainy conditions on driver behavior and accident risk. In Proceedings of the 84th Annual Meeting of the Transportation Research Board, Washington, DC, 2005.

[12] Satterthwaite S. An assessment of seasonal and weather effects on the frequency of road accidents in California. Accident Analysis \& Prevention 8(2): 87-96 (1976)

[13] Andrey J, Yagar S. A temporal analysis of rain-related crash risk. Accident Analysis \& Prevention 25(4): 465-472 (1993)

[14] Brodsky H, Hakkert A S. Risk of a road accident in rainy weather. Accident Analysis \& Prevention 20(3): 161-176 (1988)

[15] Alvarez L, Yi J. Adaptive emergency braking control in automated highway systems. In Proceedings of the 38th IEEE Conference on Decision and Control, IEEE, 1999: 3740-3745.

[16] Schinkel M, Hunt K. Anti-lock braking control using a sliding mode like approach. In American Control Conference, IEEE, 2002: 2386-2391.

[17] Wellstead P, Pettit N. Analysis and redesign of an antilock brake system controller. IEEE Proceedings-Control Theory and Applications 144(5): 413-426 (1997) 
[18] Tsiotras P, De Wit C C. On the optimal braking of wheeled vehicles. In American Control Conference, IEEE, 2000: $569-573$.

[19] Zhang D, Zheng H, Sun J, Wang Q, Wen Q, Yin A, Yang Z. Simulation study for anti-lock braking system of a light bus. In Vehicle Electronics Conference, 1999, (IVEC'99) Proceedings of the IEEE International, IEEE, 1999: 70-77.

[20] Doumiati M, Charara A, Victorino A, Lechner D. Vehicle Dynamics Estimation using Kalman Filtering: Experimental Validation. John Wiley \& Sons, 2012.

[21] Eichhorn U, Roth J. Prediction and monitoring of tyre/road friction. In XXIV FISITA CONGRESS, LONDON, 1992.

[22] Breuer B, Eichhorn U, Roth J. Measurement of tyre/roadfriction ahead of the car and inside the tyre. In International Symposium on Advanced Vehicle Control, Yokohama, Japan, 1992.

[23] Andersson M, Bruzelius F, Casselgren J, Gäfvert M, Hjort M, Hultén J, Håbring F, Klomp M, Olsson G, Sjödahl M. Road friction estimation. Saab Automobile AB, Trollhättan, Sweden (2007)

[24] Tuononen A J. Optical position detection to measure tyre carcass deflections. Vehicle System Dynamics 46(6): 471-481 (2008)

[25] Tuononen A, Hartikainen L. Optical position detection sensor to measure tyre carcass deflections in aquaplaning. International Journal of Vehicle Systems Modelling and Testing 3(3): 189-197 (2008)

[26] Tuononen A. Optical position detection to measure tyre carcass deflections and implementation for vehicle state estimation. Ph.D Thesis. Espoo (Finland): Helsinki University of Technology, 2009.

[27] Howard A, Seraji H. Vision-based terrain characterization and traversability assessment. Journal of Field Robotics 18(10): 577-587 (2001)

[28] Kuno T, Sugiura H. Detection of road conditions with CCD cameras mounted on a vehicle. Systems and computers in Japan 30(14): 88-99 (1999)

[29] Holzmann F, Bellino M, Siegwart R,Bubb H. Predictive estimation of the road-tire friction coefficient. In Computer Aided Control System Design, 2006 IEEE International Conference on Control Applications, 2006 IEEE International Symposium on Intelligent Control, IEEE, 2006: 885-890.

[30] Jokela M, Kutila M, Le L. Road condition monitoring system based on a stereo camera. In Intelligent Computer Communication and Processing, IEEE 5th International Conference on, IEEE, 2009: 423-428.

[31] Alonso J, López J, Pavón I, Recuero M, Asensio C, Arcas G, Bravo A. On-board wet road surface identification using tyre/road noise and Support Vector Machines. Applied
Acoustics 76: 407-415 (2014)

[32] Kongrattanaprasert W, Nomura H, Kamakura T, Ueda K. Automatic detection of road surface conditions using tire noise from vehicles. The lnstuute of Elecironics, Information and Communication Engineers 108: 55-60 (2009)

[33] Kongrattanaprasert W, Nomura H, Kamakura T, Ueda K. Detection of road surface conditions using tire noise from vehicles. IEEJ Transactions on Industry Applications 129: 761-767 (2009)

[34] Kongrattanaprasert W, Nomura H, Kamakura T,Ueda K. Detection of road surface states from tire noise using neural network analysis. IEEJ Transactions on Industry Applications 130: 920-925 (2010)

[35] Kongrattanaprasert W, Nomura H, Koji Ueda T K. Automatic detection of road surface states from tire noise using neural network analysis. In Proceedings of 20th International Congress on Acoustics (ICA), Sydney, Australia, 2010: 1-4.

[36] Erdogan G, Alexander L, Rajamani R. Estimation of tireroad friction coefficient using a novel wireless piezoelectric tire sensor. IEEE Sensors Journal 11(2): 267-279 (2011)

[37] Breuer B, Barz M, Bill K, Gruber S, Semsch M, Strothjohann T, Xie C. The mechatronic vehicle corner of Darmstadt University of Technology-Interaction and cooperation of a sensor tire, new low-energy disc brake and smart wheel suspension. International Journal of Automotive Technology 3(2): 63-70 (2002)

[38] Bachmann T. The Importance of The Integration of Road, Tyre And Vehicle Technologies. PIARC, 1995.

[39] Hollingum J. Autonomous radio sensor points to new applications. Sensor Review 21(2): 104-107 (2001)

[40] Khaleghian S. The application of intelligent tires and model based estimation algorithms in tire-road contact characterization. Ph.D Thesis. Virginia (USA): Virginia Polytechnic Institute and State University, 2017.

[41] Matilainen M J, Tuononen A J. Tire friction potential estimation from measured tie rod forces. In Intelligent Vehicles Symposium (IV), IEEE, 2011: 320-325.

[42] Matilainen M J, Tuononen A J. Intelligent tire to measure contact length in dry asphalt and wet concrete conditions. In Proceedings of the 11th International Symposium on Advanced Vehicle Control, Seoul, Korea, 2012: 9-12.

[43] Khaleghian S, Ghasemalizadeh O, Taheri S. Estimation of the tire contact patch length and normal load using intelligent tires and its application in small ground robot to estimate the tire-road friction. Tire Science and Technology 44(4): 248-261 (2016)

[44] Khaleghian S, Taheri S. Terrain classification using intelligent tire. Journal of Terramechanics 71: 15-24 (2017) 
[45] Niskanen A J, Tuononen A J. Three 3-axis accelerometers fixed inside the tyre for studying contact patch deformations in wet conditions. Vehicle System Dynamics 52(sup1): 287-298 (2014)

[46] Niskanen A J, Tuononen A J. Three 3-axis accelerometers on the inner liner of a tyre for finding the tyre-road contact friction indicators. In Proc. of AVEC International Symposium on Advanced Vehicle Control, Tokyo, Japan, 2014.

[47] Niskanen A J, Tuononen A J. Accelerometer tyre to estimate the aquaplaning state of the tyre-road contact. In Intelligent Vehicles Symposium (IV), IEEE, 2015: 343-348.

[48] Klein S D. Friction estimation and detection for an electric power steering system. Google Patents, 2015.

[49] Singh K B. Intelligent tire-based road friction estimation system and method. Google Patents, 2016.

[50] Singh K B, Parsons A W, Engel M. Tire slip angle estimation system and method. Google Patents, 2015.

[51] Singh K B, Parsons A W, Engel M, Suh P J M. Tire load estimation system using road profile adaptive filtering. Google Patents, 2014.

[52] Miyazaki N. Road surface friction sensor and road surface friction coefficient detector, and vehicle antilock braking device. Google Patents, 2001.

[53] Hattori Y. Method for detecting strain state of tire, device for detecting the strain state, sensor unit for the method and device, and tire provided with the sensor unit. Google Patents, 2003.

[54] Hillenmayer F, Kuchler G. System for monitoring a vehicle with pneumatic tires, signal analysis method, and vehicle tire. Google Patents, 2006.

[55] Miyoshi A, Tsurita T, Kunii M. System and method for determining tire force. Google Patents, 2007.

[56] Sistonen M. Device for measuring the friction on a surface. Google Patents, 1990.

[57] Bell L D, Bell C D. Method and apparatus for monitoring the coefficient of friction between a tire and rolling surface, particularly to provide the vehicle operator with coefficient of friction, tire tread wear out and skid warning indications. Google Patents, 1999.

[58] Abe Y, Sawa T. Dynamic friction coefficient measuring apparatus. Google Patents, 1986.

[59] Gillespie T D. Fundamentals of Vehicle Dynamics. Society of Automotive Engineers, Warrendale, PA, 1992.

[60] De Wit C C, Horowitz R, Tsiotras P. Model-based observers for tire/road contact friction prediction. In New Directions in Nonlinear Observer Design. Springer, 1999: 23-42.

[61] Claeys X, Yi J, Alvarez L, Horowitz R, de Wit C C. A dynamic tire/road friction model for $3 \mathrm{D}$ vehicle control and simulation. In Intelligent Transportation Systems, 2001. Proceedings. 2001 IEEE, IEEE, 2001: 483-488.

[62] de-Wit C, Petersen M L, Shiriaev A. A new nonlinear observer for tire/road distributed contact friction. In Decision and Control, 2003. Proceedings. 42nd IEEE Conference on, IEEE, 2003: 2246-2251.

[63] Hsiao T, Liu N-C, Chen S-Y. Robust estimation of the friction forces generated by each tire of a vehicle. In American Control Conference (ACC), IEEE, 2011: 5261-5266.

[64] Rajamani R, Phanomchoeng G, Piyabongkarn D, Lew J Y. Algorithms for real-time estimation of individual wheel tire-road friction coefficients. IEEE/ASME Transactions on Mechatronics 17(6): 1183-1195 (2012)

[65] Cho W, Yoon J, Yim S, Koo B, Yi K. Estimation of tire forces for application to vehicle stability control. IEEE Transactions on Vehicular Technology 59(2): 638-649 (2010)

[66] Rabhi A, M'sirdi N, Elhajjaji A. Estimation of contact forces and tire road friction. In Control \& Automation, 2007. MED'07. Mediterranean Conference on, IEEE, 2007: 1-6.

[67] M'sirdi N, Rabhi A, Ouladsine M, Fridman L. First and high-order sliding mode observers to estimate the contact forces. In Variable Structure Systems, VSS'06, International Workshop on, IEEE, 2006: 274-279.

[68] Singh K B. Development of an intelligent tire based tirevehicle state estimator for application to global chassis control. Virginia Polytechnic Institute and State University, 2012.

[69] Hac A, Brown T, Martens J. Detection of vehicle rollover. SAE Technical Paper, 2004.

[70] Tsourapas V, Piyabongkarn D, Williams A C, Rajamani R. New method of identifying real-time predictive lateral load transfer ratio for rollover prevention systems. In American Control Conference, 2009. ACC'09., IEEE, 2009: 439-444.

[71] Grip H F, Imsland L, Johansen T A, Kalkkuhl J C, Suissa A. Estimation of road inclination and bank angle in automotive vehicles. In American Control Conference, 2009. ACC'09., IEEE, 2009: 426-432.

[72] Chen S-K, Moshchuk N, Nardi F, Ryu J. Vehicle rollover avoidance. IEEE Control Systems 30(4): 70-85 (2010)

[73] Ryu J, Moshchuk N K, Chen S-K. Vehicle state estimation for roll control system. In American Control Conference, 2007. ACC'07, IEEE, 2007: 1618-1623.

[74] Cho K, Son H, Choi S B, Kang S. Lateral acceleration compensation of a vehicle based on roll angle estimation. In Control Applications (CCA), 2010 IEEE International Conference on, IEEE, 2010: 1363-1368.

[75] Wang J, Alexander L, Rajamani R. GPS based real-time tire-road friction coefficient identification. In Technical Report of Minnesota Department of Transportation. Minnesota, U.S. 2004. 
[76] Hahn J-O, Rajamani R,Alexander L. GPS-based real-time identification of tire-road friction coefficient. IEEE Transactions on Control Systems Technology 10(3): 331-343 (2002)

[77] Gustafsson F. Slip-based tire-road friction estimation. Automatica 33(6): 1087-1099 (1997)

[78] Doumiati M, Victorino A, Charara A, Lechner D. Estimation of road profile for vehicle dynamics motion: experimental validation. In American Control Conference (ACC), IEEE, 2011: 5237-5242.

[79] Doumiati M, Charara A, Victorino A, Lechner D. Road safety: embedded observers for estimation of vehicle's vertical tyre forces. International Journal of Vehicle Autonomous Systems 10(1-2): 117-143 (2012)

[80] Samadi B, Kazemi R, Nikravesh K Y, Kabganian M. Real-time estimation of vehicle state and tire-road friction forces. In American Control Conference, 2001. Proceedings of the 2001, IEEE, 2001: 3318-3323.

[81] Baffet G, Charara A, Lechner D, Thomas D. Experimental evaluation of observers for tire-road forces, sideslip angle and wheel cornering stiffness. Vehicle System Dynamics 46(6): 501-520 (2008)

[82] Shim T, Margolis D. Model-based road friction estimation. Vehicle System Dynamics 41(4): 249-276 (2004)

[83] Shim T, Margolis D. An analytical tyre model for vehicle simulation in normal driving conditions. International Journal of Vehicle Design 35(3): 224-240 (2004)

[84] Doumiati M, Victorino A, Charara A, Lechner D. Unscented Kalman filter for real-time vehicle lateral tire forces and sideslip angle estimation. In Intelligent Vehicles Symposium, IEEE, 2009: 901-906.

[85] Doumiati M, Victorino A, Charara A, Lechner D. A method to estimate the lateral tire force and the sideslip angle of a vehicle: Experimental validation. In American Control Conference (ACC), IEEE, 2010: 6936-6942.

[86] Doumiati M, Victorino A C, Charara A, Lechner D. Onboard real-time estimation of vehicle lateral tire-road forces and sideslip angle. IEEE/ASME Transactions on Mechatronics 16(4): 601-614 (2011)

[87] Doumiati M, Victorino A, Charara A, Lechner D. Estimation of vehicle lateral tire-road forces: a comparison between extended and unscented Kalman filtering. In Control Conference (ECC), 2009 European, IEEE, 2009: 4804-4809.

[88] Doumiati M, Victorino A, Lechner D, Baffet G, Charara A. Observers for vehicle tyre/road forces estimation: experimental validation. Vehicle System Dynamics 48(11): 1345-1378 (2010)

[89] Ghandour R, Victorino A, Doumiati M, Charara A. Tire/road friction coefficient estimation applied to road safety. In Control \& Automation (MED), 2010 18th Mediterranean
Conference on, IEEE, 2010: 1485-1490.

[90] Ghandour R, Victorino A, Charara A, Lechner D. A vehicle skid indicator based on maximum friction estimation. IFAC Proceedings Volumes 44(1): 2272-2277 (2011)

[91] Ghandour R, da Cunha F H, Victorino A, Charara A, Lechner D. Risk indicators prediction based on the estimation of tire/road forces and the maximum friction coefficient: Experimental validation. In Control \& Automation (MED), 2011 19th Mediterranean Conference on, IEEE, 2011: 700-705.

[92] Dakhlallah J, Glaser S, Mammar S, Sebsadji Y. Tire-road forces estimation using extended Kalman filter and sideslip angle evaluation. In American Control Conference, IEEE, 2008: 4597-4602.

[93] Sebsadji Y, Glaser S, Mammar S, Dakhlallah J. Road slope and vehicle dynamics estimation. In American Control Conference, IEEE, 2008: 4603-4608.

[94] Cheng Q, Correa-Victorino A, Charara A. A new nonlinear observer using unscented Kalman filter to estimate sideslip angle, lateral tire road forces and tire road friction coefficient. In Intelligent Vehicles Symposium (IV), IEEE, 2011: 709-714.

[95] Ray L R. Nonlinear tire force estimation and road friction identification: Simulation and experiments. Automatica 33(10): 1819-1833 (1997)

[96] Ray L R. Experimental determination of tire forces and road friction. In American Control Conference, 1998. Proceedings of the 1998, IEEE, 1998: 1843-1847.

[97] Jin X, Yin G. Estimation of lateral tire-road forces and sideslip angle for electric vehicles using interacting multiple model filter approach. Journal of the Franklin Institute 352(2): 686-707 (2015)

[98] Rajamani R, Piyabongkarn N, Lew J, Yi K, Phanomchoeng G. Tire-road friction-coefficient estimation. IEEE Control Systems 30(4): 54-69 (2010)

[99] Baffet G, Charara A, Lechner D. Estimation of Tire-Road Forces and Vehicle Sideslip Angle. INTECH Open Access Publisher, 2008.

[100] Baffet G, Charara A, Lechner D. Estimation of vehicle sideslip, tire force and wheel cornering stiffness. Control Engineering Practice 17(11): 1255-1264 (2009)

[101] Zhang W, Ding N, Yu G, Zhou W. Virtual sensors design in vehicle sideslip angle and velocity of the centre of gravity estimation. In Electronic Measurement \& Instruments, 2009. ICEMI'09. 9th International Conference on, IEEE, 2009: 3-652-653-656.

[102] Baffet G, Charara A, Dherbomez G. An observer of tire-road forces and friction for active security vehicle systems. IEEE/ASME Transactions on Mechatronics 12(6): 651-661 (2007) 
[103] Ahn C S. Robust estimation of road friction coefficient for vehicle active safety systems. The University of Michigan, 2011.

[104] Zhang H, Huang X, Wang J, Karimi H R. Robust energy-to-peak sideslip angle estimation with applications to ground vehicles. Mechatronics 30: 338-347 (2015)

[105] Zhu T, Zheng H. Application of unscented Kalman filter to vehicle state estimation. In Computing, Communication, Control, and Management, 2008. CCCM'08. ISECS International Colloquium on, IEEE, 2008: 135-139.

[106] Pan Z, Zong C, Zhang J, Xie X, Dong Y. UKF and EKF estimator design based on a nonlinear vehicle model containing UniTire model. In Mechatronics and Automation, 2009. ICMA 2009. International Conference on, IEEE, 2009: 4780-4784.

[107] Chu L, Shi Y, Zhang Y, Liu H, Xu M. Vehicle lateral and longitudinal velocity estimation based on Adaptive Kalman Filter. In Advanced Computer Theory and Engineering (ICACTE), 2010 3rd International Conference on, IEEE, 2010: V3-325-V323-329.

[108] Chu L, Zhang Y, Shi Y, Xu M, Liu M. Vehicle lateral and longitudinal velocity estimation based on Unscented Kalman Filter. In Education Technology and Computer (ICETC), 2010 2nd International Conference on, IEEE, 2010: V3-427-V423-432.

[109] Hsu Y-H J, Laws S M, Gerdes J C. Estimation of tire slip angle and friction limits using steering torque. IEEE Transactions on Control Systems Technology 18(4): 896-907 (2010)

[110] Ray L R. Nonlinear state and tire force estimation for advanced vehicle control. IEEE Transactions on Control Systems Technology 3(1): 117-124 (1995)

[111] Gao X, Yu Z, Neubeck J, Wiedemann J. Sideslip angle estimation based on input-output linearisation with tireroad friction adaptation. Vehicle System Dynamics 48(2): 217-234 (2010)

[112] Pacejka H B, Bakker E. The magic formula tyre model. Vehicle System Dynamics 21(S1): 1-18 (1992)

[113] Pacejka H, Besselink I. Magic formula tyre model with transient properties. Vehicle System Dynamics 27(S1): 234-249 (1997)

[114] Bakker E, Nyborg L, Pacejka H B. Tyre modelling for use in vehicle dynamics studies. SAE Technical Paper, 1987.

[115] Pacejka H B, Sharp R S. Shear force development by pneumatic tyres in steady state conditions: a review of modelling aspects. Vehicle System Dynamics 20(3-4): 121-175 (1991)

[116] van Oosten J J, Bakker E. Determination of magic tyre model parameters. Vehicle System Dynamics 21(S1):
19-29 (1992)

[117] Kim C-S, Hong K-S, Yoo W-S, Park Y-W. Tire-road friction estimation for enhancing the autonomy of wheeldriven vehicles. In Control, Automation and Systems, 2007. ICCAS'07. International Conference on, IEEE, 2007: 273-277.

[118] Yi K, Hedrick K, Lee S-C. Estimation of tire-road friction using observer based identifiers. Vehicle System Dynamics 31(4): 233-261 (1999)

[119] Jayachandran R, Ashok S D, Narayanan S. Fuzzy Logic based Modelling and Simulation Approach for the estimation of Tire Forces. Procedia Engineering 64: 1109-1118 (2013)

[120] Svendenius J. Tire modeling and friction estimation. $\mathrm{PhD}$ Theses, 2007.

[121] Villagra J, d'Andréa-Novel B, Fliess M, Mounier H. A diagnosis-based approach for tire-road forces and maximum friction estimation. Control Engineering Practice 19(2): 174-184 (2011)

[122] Patra N, Datta K. Observer based road-tire friction estimation for slip control of braking system. Procedia Engineering 38: 1566-1574 (2012)

[123] Svendenius J, Gäfvert M, Bruzelius F, Hultén J. Experimental validation of the brush tire model 5. Tire Science and Technology 37(2): 122-137 (2009)

[124] Pacejka H. Tire and Vehicle Dynamics. Elsevier, 2005.

[125] Erdogan G. Lateral and longitudinal tire forces. In Tire Modeling lecture, 2009.

[126] Chen Y, Wang J. Adaptive vehicle speed control with input injections for longitudinal motion independent road frictional condition estimation. IEEE Transactions on Vehicular Technology 60(3): 839-848 (2011)

[127] Andersson M, Bruzelius F, Casselgren J, Hjort M, Löfving S, Olsson G, Rönnberg J, Sjödahl M, Solyom S, Svendenius J. Road friction estimation Part II. Technical Report, IVSS project 2004: 17750, 2010, available at www. ivss. com, 2010.

[128] Nishihara O, Masahiko K. Estimation of road friction coefficient based on the brush model. Journal of Dynamic Systems, Measurement, and Control 133(4): 041006 (2011)

[129] Yamazaki S, Furukawa O, Suzuki T. Study on real time estimation of tire to road friction. Vehicle System Dynamics 27(S1): 225-233 (1997)

[130] De Wit C C, Olsson H, Astrom K J, Lischinsky P. A new model for control of systems with friction. IEEE Transactions on Automatic Control 40(3): 419-425 (1995)

[131] De Wit C C, Tsiotras P. Dynamic tire friction models for vehicle traction control. In Decision and Control, 1999. Proceedings of the 38th IEEE Conference on, IEEE, 1999: 
$3746-3751$

[132] Alvarez L, Yi J, Horowitz R, Olmos L. Dynamic friction model-based tire-road friction estimation and emergency braking control. Journal of Dynamic Systems, Measurement, and Control 127(1): 22-32 (2005)

[133] Matuško J, Petrović I, Perić N. Neural network based tire/road friction force estimation. Engineering Applications of Artificial Intelligence 21(3): 442-456 (2008)

[134] Dieckmann T. Assessment of road grip by way of measured wheel variables. In XXIV FISITA CONGRESS, LONDON, 1992.

[135] Hwang W, Song B-s. Road condition monitoring system using tire-road friction estimation. In Proceedings of AVEC, 2000: 437-442.

[136] Fischlein H, Gnadler R, Unrau H-J. The influence of the track surface structure on the frictional force behaviour of passenger car tyres in dry and wet track surface conditions. ATZ Worldwide 103(10): 20-24 (2001)

[137] Germann S, Wurtenberger M, Daiß A. Monitoring of the friction coefficient between tyre and road surface. In Proceedings of the third IEEE Conference on Control Applications, 1994: 613-618.

[138] Müller S, Uchanski M, Hedrick K. Estimation of the maximum tire-road friction coefficient. Journal of Dynamic Systems, Measurement, and Control 125(4): 607-617 (2003)

[139] Wang J, Alexander L, Rajamani R. Friction Estimation on highway vehicles using longitudinal measurements. Journal of Dynamic Systems, Measurement, and Control 126(2): 265-275 (2004)

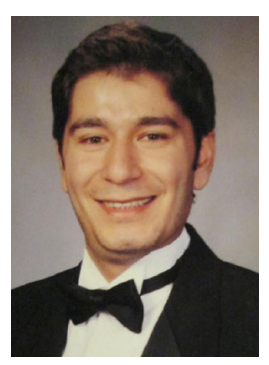

Seyedmeysam KHALEGHIAN. He received his B.S. degree in mechanical engineering from Sharif University of Technology, Tehran, Iran, in 2008, his M.S. degree in mechanical engineering from University of Tehran, Tehran, Iran, in 2011, and his Ph.D. degree in engineering mechanics from Department of Biomedical
[140] Lee C, Hedrick K, Yi K. Real-time slip-based estimation of maximum tire-road friction coefficient. IEEE/ASME Transactions on Mechatronics 9(2): 454-458 (2004)

[141] Persson B N. Theory of rubber friction and contact mechanics. The Journal of Chemical Physics 115(8): 3840-3861 (2001)

[142] Persson B N. Rubber friction: role of the flash temperature. Journal of Physics: Condensed Matter 18(32): 7789 (2006)

[143] Lorenz B, Oh Y, Nam S, Jeon S, Persson B. Rubber friction on road surfaces: Experiment and theory for low sliding speeds. The Journal of Chemical Physics 142(19): 194701 (2015)

[144] Klüppel M, Heinrich G. Rubber friction on self-affine road tracks. Rubber chemistry and technology 73(4): 578-606 (2000)

[145] Le Gal A, Klüppel M. Investigation and modelling of rubber stationary friction on rough surfaces. Journal of Physics: Condensed Matter 20(1): 015007 (2007)

[146] Motamedi M, Taheri S, Sandu C. Rubber-road contact: Comparison of physics-based theory and indoor experiments. Tire Science and Technology 44(3): 150-173 (2016)

[147] Ignatiev P, Wies B. Tire road interaction: Improved modeling, simulation and experimental validation of tire road-interaction. Tire Technology International 8(3): 14-18 (2016)

[148] Henry J J. The relationship between texture and pavement friction. Tire Science and Technology 6(4): 215-232 (1978)

[149] ASTM E. Standard Practice for Calculating International Friction Index of a Pavement Surface. ASTM International, 2003.

Engineering and Mechanics at Virginia Polytechnic Institute and State University. $\mathrm{He}$ is currently a postdoctoral fellow at the Center for Tire Research (CenTire) Virginia Tech working on intelligent tire based and vehicle dynamic based friction estimation algorithms. His research interests are vehicle dynamics, state estimation, contact mechanics, tire mechanics, and experimental and numerical stress analysis. 